\title{
Identification and analysis of common bean (Phaseolus vulgaris L.) transcriptomes by massively parallel pyrosequencing
}

\author{
Venu Kalavacharla, ${ }^{1,4^{*}}$, Zhanji Liu', Blake C Meyers², Jyothi Thimmapuram³ and Kalpalatha Melmaiee
}

\begin{abstract}
Background: Common bean (Phaseolus vulgaris) is the most important food legume in the world. Although this crop is very important to both the developed and developing world as a means of dietary protein supply, resources available in common bean are limited. Global transcriptome analysis is important to better understand gene expression, genetic variation, and gene structure annotation in addition to other important features. However, the number and description of common bean sequences are very limited, which greatly inhibits genome and transcriptome research. Here we used 454 pyrosequencing to obtain a substantial transcriptome dataset for common bean.

Results: We obtained 1,692,972 reads with an average read length of 207 nucleotides (nt). These reads were assembled into 59,295 unigenes including 39,572 contigs and 19,723 singletons, in addition to 35,328 singletons less than $100 \mathrm{bp}$. Comparing the unigenes to common bean ESTs deposited in GenBank, we found that 53.40\% or 31,664 of these unigenes had no matches to this dataset and can be considered as new common bean transcripts. Functional annotation of the unigenes carried out by Gene Ontology assignments from hits to Arabidopsis and soybean indicated coverage of a broad range of GO categories. The common bean unigenes were also compared to the bean bacterial artificial chromosome (BAC) end sequences, and a total of $21 \%$ of the unigenes $(12,724)$ including 9,199 contigs and 3,256 singletons match to the 8,823 BAC-end sequences. In addition, a large number of simple sequence repeats (SSRs) and transcription factors were also identified in this study.

Conclusions: This work provides the first large scale identification of the common bean transcriptome derived by 454 pyrosequencing. This research has resulted in a 150\% increase in the number of Phaseolus vulgaris ESTs. The dataset obtained through this analysis will provide a platform for functional genomics in common bean and related legumes and will aid in the development of molecular markers that can be used for tagging genes of interest. Additionally, these sequences will provide a means for better annotation of the on-going common bean whole genome sequencing.
\end{abstract}

\section{Background}

Phaseolus vulgaris or common bean is the most important edible food legume in the world. It provides $15 \%$ of the protein and $30 \%$ of the caloric requirement to the world's population, and represents $50 \%$ of the grain legumes consumed worldwide [1]. Common bean has several market classes, which include dry beans, canned beans, and green beans. The related legume soybean

\footnotetext{
* Correspondence: vkalavacharla@desu.edu

${ }^{1}$ College of Agriculture \& Related Sciences, Delaware State University, Dover, DE 19901, USA

Full list of author information is available at the end of the article
}

(Glycine max), which is one of the most important sources of seed protein and oil content belongs to the same group of papilionoid legumes as common bean. Common bean and soybean diverged nearly 20 million years ago around the time of the major duplication event in soybean $[2,3]$. Synteny analysis indicates that most segments of any one common bean linkage group are highly similar to two soybean chromosomes [4]. Since $P$. vulgaris is a true diploid with a genome size estimated to be between 588 and 637 mega base pairs (Mbp) [5-7], it will serve as a model for understanding the $\sim 1,100$ million base pairs (Mbp) soybean genome

\section{Biomed Central}


[1]. Common bean is also related to other members of the papilionid legumes including cowpea (Vigna unguiculata) and pigeon pea (Vigna radiata). Therefore, better knowledge of the common bean genome will facilitate better understanding of other important legumes as well as the development of comparative genomics resources.

The common bean genome is currently being sequenced [8]. When the sequencing of the genome is complete, this will require the prediction, annotation and validation of the expressed genes in common bean. The availability of large sets of annotated sequences as derived by identification, sequencing, and validation of genes expressed in the common bean will help in the development of an accurate and complete structural annotation of the common bean genome, a valid transcriptome map, and the identification of the genetic basis of agriculturally important traits in common bean. The transcriptome sequences will also help in the identification of transcription factors and small RNAs in common bean, understanding of gene families, and very importantly the development of molecular markers for common bean.

To date there are several relevant and important publications in common bean transcriptome sequencing and bioinformatics analyses. Ramirez et al. [9] sequenced 21,026 ESTs from various cDNA libraries (nitrogen-fixing root nodules, phosphorus-deficient roots, developing pods, and leaves) derived from the Meso-American common bean genotype Negro Jamapa 81, and leaves from the Andean genotype G19833. Approximately 10,000 of these identified ESTs were classified into 2,226 contigs and 7,969 singletons.

Melotto et al. [10] constructed three cDNA libraries from the common bean breeding line SEL1308. These libraries were comprised of 19-day old trifoliate leaves, 10-day old shoots, and 13-day old shoots (inoculated with Colletotrichum lindemuthianum). Of the 5,255 single-pass sequences obtained from this work, trimming and clustering helped identify 3,126 unigenes, and of these only 314 unigenes showed similarity to sequences from the existing database.

Tian et al. [11] constructed a suppression substractive cDNA library to identify genes involved in response to phosphorous starvation. Six-day old seedlings from the genotype G19833 were exposed to high and low phosphorus (five and $1,000 \mu \mathrm{mol} / \mathrm{L}$ ) respectively and the poly $(\mathrm{A}+)$ RNA derived from total shoot and root RNA from plants in these conditions was used for construction of the libraries. After dot-blot hybridization and identification of differentially expressed clones, full-length cDNAs were identified from cDNA libraries constructed from the low and high P exposure experiments. Differentially expressed genes were characterized into five functional groups, and these authors were able to further classify 72 genes by comparison to the GenBank non-redundant database using BLASTx values less than $1.0 \times 1 \mathrm{e}^{-2}$ ).

Thibivilliers et al. [7] identified 6, 202 new common bean ESTs (out of a total of 10,221 ESTs) by using a substractive cDNA library constructed from the common bean rust resistant-cultivar Early Gallatin. This cultivar was inoculated with races 49 (avirulent on genotypes such as Early Gallatin carrying the rust resistance locus $U r-4$ ) and 41 (a virulent race that is not recognized by $U r-4)$. In order to identify genes which are differentially expressed, suppression substractive expression experiments were carried out to identify sequences which were up-regulated in response to susceptible and resistant host-pathogen interactions.

Despite these studies in common bean, there is still a paucity in the number of common bean ESTs and genes that have been deposited in GenBank ( 83,448 ESTs, as of September, 2010) compared to other legume and plant models. Therefore, there is a need for deeper coverage and EST sequences from diverse common bean tissues and genotypes.

There has been an evolution in sequencing technologies starting with the traditional dideoxynucleotide sequencing to capillary-based sequencing to current "next-generation" sequencing $[12,13]$. The emergence of next-generation sequencing technologies has substantially helped advance plant genome research, particularly for non-model plant species [14]. Next generation sequencing strategies typically have the ability to generate millions of reads of sequences at a time, without the need for cloning of the fragment libraries; these are faster than traditional capillary-based methods which may be limited to 96 samples in a run and require the nucleic acid material (DNA or complementary DNA; cDNA) to be cloned into a plasmid and amplified by Escherichia coli (E. coli). Therefore, cloning bias that is typically present in genome sequencing projects can be avoided, although depending on the specific platform used for next generation sequencing, there may be other specific biases involved. An advantage of some next generation sequencing technologies is that information on genome organization and layout may not be necessary $a$ priori. The Roche 454 method uses the pyrophosphate molecule released when nucleotides are incorporated by DNA polymerase into the growing DNA chain to fuel reactions that result in the detection of light resulting from cleavage of oxyluciferin by luciferase [15]. Using an emulsion PCR approach, it has the ability to sequence 400 to 500 nucleotides of paired ends and produces approximately 400-600 Mbp per run. This method has been applied to genome [16] and transcriptome [17-19] sequencing due to its high throughput, coverage, and savings in cost. 
In $A$. thaliana, pyrosequencing has been tested successfully to verify whether this technology is able to provide an unbiased representation of transcripts as compared to the sequenced genome. Using messenger RNA (mRNA) derived from Arabidopsis seedlings, Weber and colleagues [20] identified 541,852 ESTs which accounted for nearly 17,449 gene loci and thus provided very deep coverage of the transcriptome. The analysis also revealed that all regions of the mRNA transcript were equally represented therefore removing issues of bias, and very importantly, over 16,000 of the ESTs identified in this research were novel and did not exist in the existing EST database. Therefore, these researchers concluded that the pyrosequencing platform has the ability to aid in gene discovery and expression analysis for non-model plants, and could be used for both genomic and transcriptomic analysis.

In the legume Medicago truncatula, the 454 technology has been used to generate 252,384 reads with average (cleaned) read length of 92 nucleotides [16], with a total of 184,599 unique sequences generated after clustering and assembly. Gene ontology (GO) assignments from matches to the completed Arabidopsis sequence showed a broad coverage of the GO categories. Cheung and colleagues [17] were also able to map 70,026 reads generated in this research to 785 Medicago BAC sequences. In their analysis of the maize shoot apical meristem, Emrich and colleagues [16] discovered 261,000 ESTs, annotated more than 25,000 maize genomic sequences, and identified $\sim 400$ maize transcripts for which homologs have not been identified in any other species. The value of this approach in novel gene/EST discovery is underlined by the fact that nearly $30 \%$ of the ESTs identified in this study did not match the $\sim 648,000$ maize ESTs in the databases. Velasco and colleagues [21] generated a draft genome of grape, Vitis vinifera Pinot Noir by using a combination of Sanger sequencing and 454 sequencing. They identified approximately 29,585 predicted genes of which $96.1 \%$ could be assigned to genetic linkage groups (LGs). Many of the genes identified have potential implications on grapevine cultivation including those that influence wine quality, and response to pathogens. Detailed analysis was also carried out to identify sequences related to disease resistance, phenolic and terpenoid pathways, transcription factors, repetitive elements, and non-coding RNAs (including microRNAs, transfer RNAs, small nuclear RNAs, ribosomal RNAs and small nucleolar RNAs).

Sequences obtained in common bean by deep sequencing can be mapped onto common bean maps by using syntenic relationships between common bean and soybean; these two species diverged over 19 MYA. McClean et al. [22] determined syntenic relationships between common bean and soybean by taking genetically positioned transcript loci and mapping to the soybean 1.01 pseudochromosome assembly. Since prior evidence has shown that almost every common bean locus maps to two soybean locations (recent diploidy and polyploidy respectively), and a genome assembly is not yet available in common bean, this synteny can be effectively utilized. Therefore, by referencing common bean loci with unknown physical map positions (in common bean) to syntenic regions in soybean, and then referencing back to the common bean genetic map, approximate locations of common bean transcript loci were determined. Using this method, the authors [22] were able to determine median physical-to-genetic distance ratio in common bean to be $\sim 120 \mathrm{~Kb} / \mathrm{cM}$ (based on the soybean physical distance derived from the pseudochromosome assembly). This allowed the placing of $\sim 15,000$ EST contigs and singletons on the common bean map, and this strategy will allow for the discovery and chromosomal locations of genes controlling important traits in both common bean and soybean. Therefore, until the common bean genome is completed, we can now use synteny with soybean to determine more accurate locations of common bean transcripts.

\section{Results and Discussion}

\section{Generation of ESTs from Phaseolus vulgaris}

Since the combined total number of common bean ESTs that have been deposited in Genbank (as of September 2010) is $\sim 83,000$, we sought to increase the diversity and number of these sequences to be useful for functional genomics and molecular breeding studies. We generated cDNA libraries from four plant tissues: leaves, flowers, roots derived from the common bean cultivar "Sierra", and pods derived from the common bean breeding line "BAT93." Even though the genotype that was chosen for the common bean genome sequencing project is G19833, there is considerable value in generating transcriptomic sequences from these additional genotypes. Sierra is a common bean cultivar released by Michigan State University with improved disease resistance, competitive yield, and upright growth habit. Additionally, disease resistance in Sierra includes rust resistance, field tolerance to white mold, and resistance to Fusarium wilt [23]. The breeding line BAT93 is one of the parents of the core common bean mapping populations, and therefore, understanding and identification of sequences expressed in the developing pod is very useful. BAT93 also carries resistances to multiple diseases. The sequence data obtained from this work will also be very useful in identifying single nucleotide polymorphism (SNP) loci when compared to sequences derived from other genotypes in the work by Ramirez et al. [9], Melotto et al. [10] and Thibivilliers et al. [7]. 
The use of next-generation sequencing for transcriptome and genome studies has been well documented (as discussed in background). Given the paucity of available common bean sequences and our interest in generating sequence reads long enough to be useful for the design of primers for mapping onto the common bean map, we chose the Roche 454 sequencing method (see materials and methods). cDNAs derived from the RNA of the four tissues were tagged with sequence tags that would help identify tissue of origin after sequencing and assembly of data. After normalization, library construction and sequencing, sequences were assembled and annotated (see materials and methods) resulting in the generation of $\sim 1.6$ million reads, with an average length of 207 nucleotides (nt) and a total length of $350 \mathrm{Mbp}$ derived from three bulk 454 runs. These reads were assembled using gsAssembler (Newbler, from Roche, http://www.roche-applied-science.com), into 39,572 contigs and 55,051 singletons. Of these singletons, 35,328 were determined to be less than 100 nucleotides (nt). Therefore, sequences derived from this study serve as an important first step to deriving a larger transcriptomic set of sequences in common bean and additionally demonstrate the value of next-generation sequencing. Further, these common bean sequences will be important for discovery of orthologous genes in other socalled "orphan legumes" [24]. Assembly statistics for the 454 reads are shown in Table 1 . Of the 1.6 million reads, we were able to assemble $75 \%$ of the reads. The average length of contigs was $473 \mathrm{nt}$ and for singletons 103 nt (Table 2). For the purposes of this work, we consider the 39,572 contigs and 19,723 singletons which are longer than $100 \mathrm{nt}$ collectively as unigenes (totalling 59, 295). The number of contigs and singletons with respective sizes are shown in Table 2. The largest number of contigs $(11,597)$ was in the 200-299 nt range, followed by 9,696 contigs in the 100-199 nt range. There were 5,438 contigs which were $>1,000 \mathrm{nt}$. The longest contig length was 3,183 nt.

In order to determine the number of reads which make up any particular contig in the assembly, we

Table 1 Assembly statistics of common bean 454 reads

\begin{tabular}{cc}
\hline Name & No. \\
\hline Total reads & $1,692,972$ \\
Reads fully assembled & $1,280,774$ \\
Reads partially assembled & 245,452 \\
Repeats & 53,136 \\
Outliers & 58,559 \\
Contigs & 39,572 \\
Singletons & 55,051 \\
Singletons above 100 bp & 19,723 \\
Unigenes (contigs + singletons above 100 nt) & 59,295
\end{tabular}

Table 2 Sequence length distribution of assembled contigs and singletons

\begin{tabular}{ccc}
\hline Nucleotide length (nt) & Contigs & Singletons \\
\hline$<100$ & 19 & 35,328 \\
$100-199$ & 9,496 & 5,064 \\
$200-299$ & 11,597 & 14,639 \\
$300-399$ & 3,376 & 20 \\
$400-499$ & 2,451 & - \\
$500-599$ & 1,808 & - \\
$600-699$ & 1,489 & - \\
$700-799$ & 1,329 & - \\
$800-899$ & 1,294 & - \\
$900-999$ & 1,275 & - \\
$>1000$ & 5,438 & - \\
Total & 39,572 & 55,051 \\
Maximum length & $3,183 \mathrm{nt}$ & - \\
Average length & 473 & 103 \\
\hline
\end{tabular}

determined the number of reads versus number of contigs (Table 3). In our unigenes sequences, 22,723 contigs were comprised of 2-10 reads (minimum read range).

\section{Comparative analysis with existing Phaseolus vulgaris ESTs}

Most of the common bean ESTs available in GenBank are derived from genotypes such as Early Gallatin, Bat 93, Negro Jamapa 81, and G19833 [7]. In order to identify new $P$. vulgaris sequences among the 454 unigene set that we generated, a BLASTn search (e-value $<1 \mathrm{e}^{-}$ ${ }^{10}$ ) against the common bean ESTs in GenBank was carried out and revealed that $27,631(46.60 \%)$ of the 454 unigenes matched known ESTs. Thus 31,664 unigenes (18,087 contigs and 13,577 singletons; $53.40 \%)$ can be considered as new $P$. vulgaris unigenes.

The 83,947 common bean EST sequences (as of October 1,2010 ) can be assembled into about 20,000 unique sequences. These new sequences significantly enrich by approximately $150 \%$ the number of transcripts of this important legume and provide a significant resource for discovering new genes, developing molecular markers

Table 3 Summary of component reads per contig.

\begin{tabular}{ll}
\hline Number of reads & Number of contigs \\
\hline $2-10$ & 22,723 \\
$11-20$ & 3,920 \\
$21-30$ & 2,087 \\
$31-40$ & 1,526 \\
$41-50$ & 1,137 \\
$51-100$ & 3,332 \\
$101-150$ & 1,435 \\
$151-200$ & 715 \\
$>200$ & 1,999 \\
\hline
\end{tabular}


for future genetic linkage and QTL analysis, and comparative studies with other legumes, and will help in the discovery and understanding of genes underlying agriculturally important traits in common bean.

\section{Comparison with common bean BAC-end sequences}

Recently, a BAC library for common bean genotype G19833 was constructed [25], and a draft FingerPrinted Contig (FPC) physical map has been released using the BAC-end sequences from this work (Genbank EI415689-EI504705). This data set contains 89,017 BAC-end sequences. The FPC physical map makes it possible to map some 454 unigenes into the bean physical map. All the 454 unigenes were compared to the BAC-end sequences by BLASTN (e-value $<1 \mathrm{e}^{-10}$ ) according to McClean et al [22]. As a result, a total of 12,725 unigenes including 9,199 contigs and 3,256 singletons (21\% of the unigenes), were mapped to the available 8,823 BAC-end sequences.

\section{Functional annotation of the $P$. vulgaris unigenes- \\ Comparison to Arabidopsis}

The common bean unigene set was compared to predicted Arabidopsis protein sequences by using BLASTX. A total of 26,622 (44.90\%) of the unigenes had a significant match with the annotated Arabidopsis proteins, and were assigned putative functions (Figure 1). However, $55.10 \%(32,673)$ of the common bean unigenes had no significant match and therefore could not be classified into gene ontology (GO) categories. The comparison of the distribution of $P$. vulgaris unigenes among GO molecular function groups with that of $A$. thaliana suggests that this 454 unigene set is broadly representative of the $P$. vulgaris transcriptome. Unigenes with positive matches to the Arabidopsis proteins were grouped into 20 categories (Figure 1). The largest proportion of the functionally assigned unigenes fell into seven categories: unknown (30.13\%), nucleotide metabolism $(9.50 \%)$, protein metabolism $(9.41 \%)$, plant development and senescence $(7.27 \%)$, stress defense (9.04\%), signal transduction (7.11\%) and transport (7.67\%).

\section{Functional comparison to soybean}

All of the common bean unigenes were used to compare with soybean peptide sequences $(55,787)$ by BLASTX (Figure 2). As a result, a total of $63.31 \%(37,538)$ unigenes have a good match to soybean peptide sequences. Therefore the number of common bean matches to soybean sequences was significantly higher $(\sim 1.4 \times)$ compared to Arabidopsis and may reflect the larger number of predicted genes in soybean compared to Arabidopsis. These sequences can be used for discovery of not only common bean genes but also for validation of predicted soybean genes.

\section{Comparison of $P$. vulgaris unigenes with those in $M$. truncatula, G. max, L japonicus, A. thaliana and O. sativa} We were also interested in understanding the relationship of common bean unigenes in this study to those that have been identified in other legume models and the model plants Arabidopsis and rice with larger sequence collections. We also wanted to determine the unique and shared sequences between common bean, Medicago, lotus and soybean, and also those that are shared between common bean, Arabidopsis and rice. Nearly $54 \%(31,880)$ of the common bean unigenes have homology to Medicago, $44 \%(25,837)$ have homology to lotus, and $63 \%(37,538)$ have homology to soybean (Figure 3A). Approximately $72 \%(42,270)$ of common bean unigenes are shared between the four legume species (common bean, lotus, Medicago and soybean). We also determined that $54 \%(31,992)$ of the common bean unigenes are shared with Arabidopsis and 99\% $(58,716)$ are

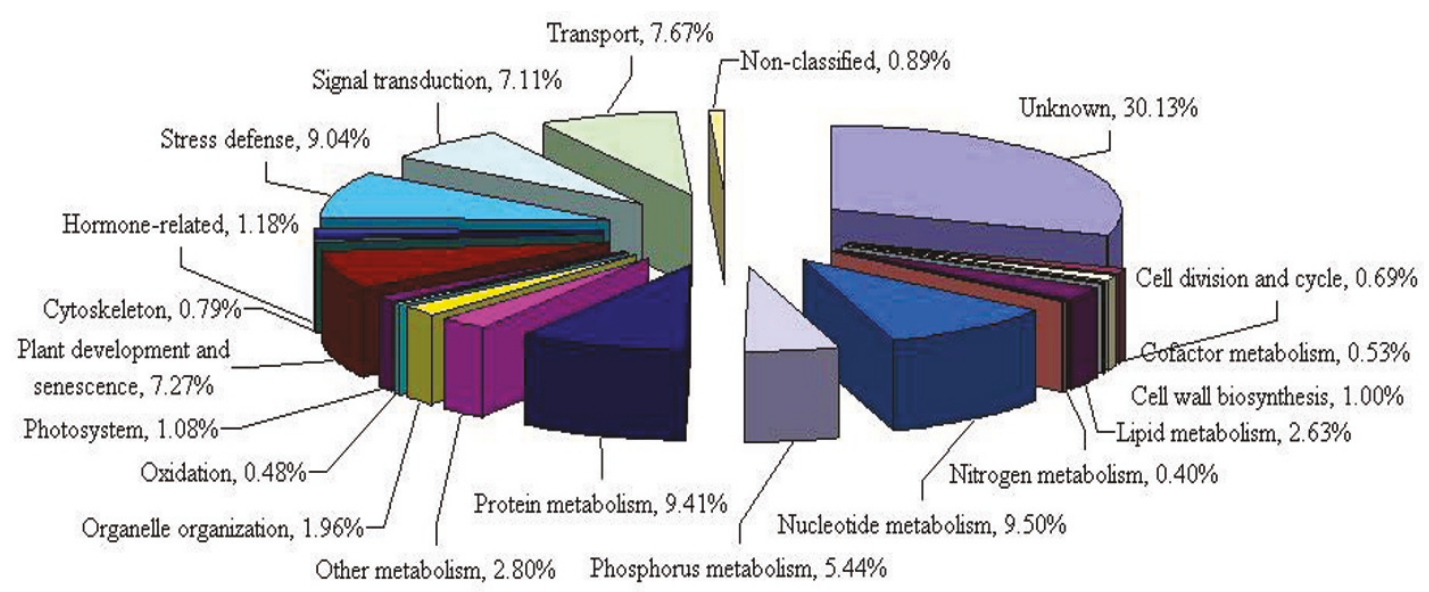

Figure 1 Functional classification of $P$. vulgaris unigenes according to the Arabidopsis peptide sequences 


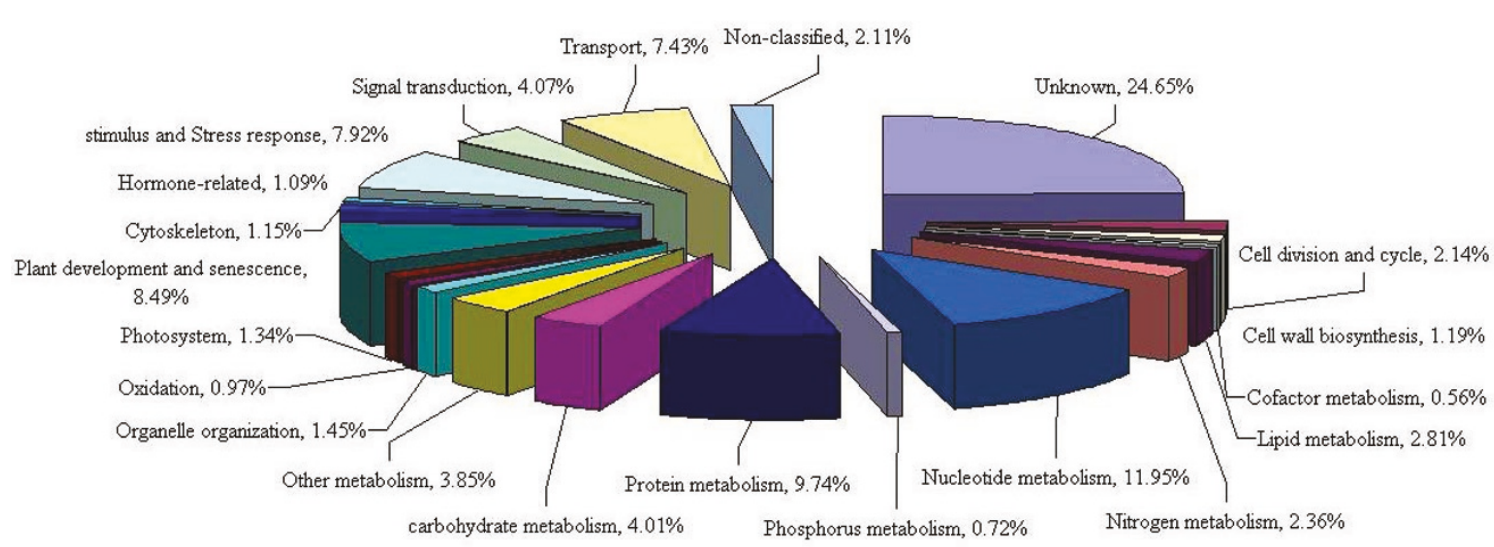

Figure 2 Functional classification of $P$. vulgaris unigenes according to the soybean peptide sequences.

shared with rice. When compared to Medicago, soybean and lotus, $28 \%(16,525)$ of the unigenes are unique to common bean whereas only $0.43 \%$ (254) of the unigenes are unique to common bean when compared to Arabidopsis and rice (Figure 3B).

As seen in the comparison to the Arabidopsis transcriptome, the most abundant category was comprised of $30.13 \%$ of the unigenes with unknown functions which was consistent with the previous study by Thibivilliers et al. [7], who found that $31.9 \%$ of common bean ESTs from bean rust-infected plants had an unknown function. They also found that $15.3 \%$ of those ESTs fell into signal transduction and nucleotide metabolism classes. Similarly, our results found that $16.61 \%$ of 454 unigenes belonged to signal transduction and nucleotide metabolism. Additionally, this analysis showed that $9.04 \%$ of the unigenes belong to the stress defense category. These unigenes provide a new and additional source for mining stress-regulated and defense response genes. Interestingly, Wong et al. [26] identified a common bean antimicrobial peptide with the ability to inhibit the human immunodeficiency virus (HIV)-1 reverse transcriptase. This 47-amino acid peptide was also found to inhibit fungi such as Botrytis cinerea, Fusarium oxysporum and Mycosphaerella arachidicola. We used the corresponding nucleotide sequence from this peptide to search against the 454 sequences in this report, and discovered one unigene represented by contig03541 with a nucleotide length of 450 bases. Search of this sequence against the NCBI non-redundant database identified homology to a plant defensin peptide from legumes such as mung bean, soybean, Medicago, and yam-bean (Pachyrhizus erosus), and it is possible that this is a gene that is specific to legumes.

\section{Validation of common bean reference genes}

Thibivilliers et al. [7] compared several housekeeping genes for use as a common bean reference for qRT-PCR experiments. They tested three bean genes TC197 (guanine nucleotide-binding protein beta subunit-like protein), TC127 (ubiquitin), and TC185 (tubulin beta chain), and the common bean homologs of the soybean genes cons6 (coding for an F-box protein family), cons7 (a metalloprotease), and cons15 (a peptidase S16). These researchers concluded that cons7 was the most stably expressed for their experimental conditions. Likewise, Libault et al. [27] also identified cons 7 to be stably expressed and to be useful as a reference gene for quantitative studies in soybean, and with the confirmation in our studies can possibly be used for other legume gene expression experiments. Therefore, for our experiments, we used the Gmcons7 primers and verified expression in the Sierra genotype (please see Figure 4, lane 57); this was then used as an endogenous control, and used in leaf tissue as a reference gene for expression analysis of common bean contigs.

Quantification of tissue-specific expression of the common bean transcriptome

When the cDNA libraries were created, the four tissues were tagged using a molecular barcode, based on their source of either leaves, roots, flowers or pods (see materials and methods) so that we could determine possible origin of tissues of the transcripts. The tags can be used to describe the presence or degree of tissue-specific expression of the unigenes. The distribution of these tags among the four tissues is shown in Figure 5. About 69\% $(41,161$ unigenes) of the unigenes were present in leaves, $52 \%(30,914$ unigenes) were present in flowers, $42 \%$ (24,725 unigenes) were present in roots, and 36\% (21,063 unigenes) were present in pods. Among all the unigenes, $27 \%$ (16,155 unigenes) were observed only in leaves, $8 \%$ (4,805 unigenes) only in roots, $11 \%$ ( 6,810 unigenes) only in flowers, and $6 \%$ (3,321 unigenes) only in pods.

In our analysis of the 454 data, we found that 28,204 contigs were composed of transcripts that were derived 

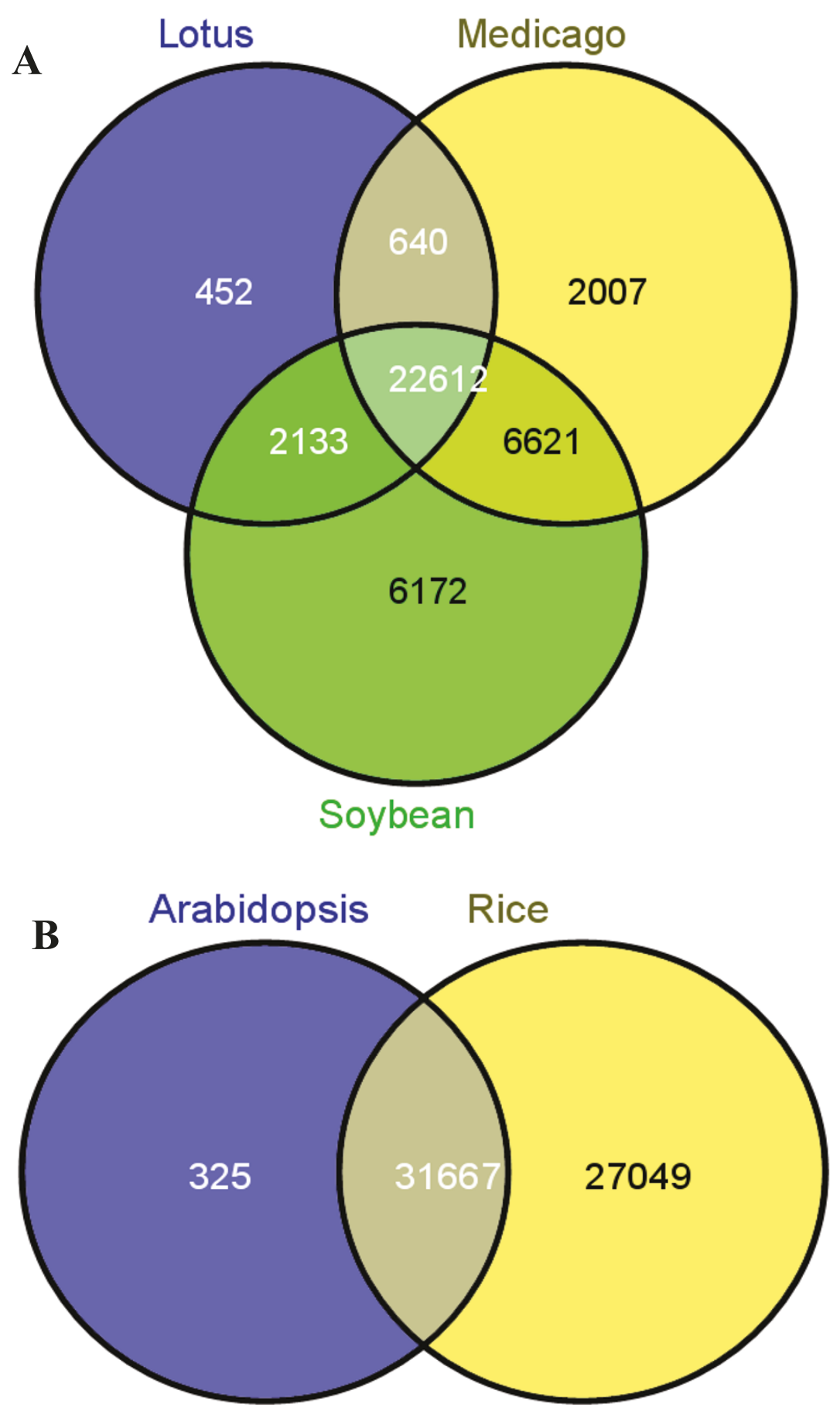

Figure 3 Venn diagram of $P$. vulgaris unigenes showing common and unique unigenes compared to legume and non-legume species (A) P. vulgaris unigenes compared to soybean, Medicago and lotus. (B) P. vulgaris unigenes compared to Arabidopsis and rice. Numbers in the Venn diagram refer to the number of $P$. vulgaris unigenes having hits to each plant species, as labeled.

from multiple tissues (Table 4). The tagging of the cDNA libraries will be very useful in order to verify and validate global gene expression patterns and understanding both shared and unique transcripts between and among the tissues in this study. Equally significant is the ability to capture rarely expressed transcripts. Since normalization was carried out (as seen in methods), the large number of transcripts derived from leaves is 


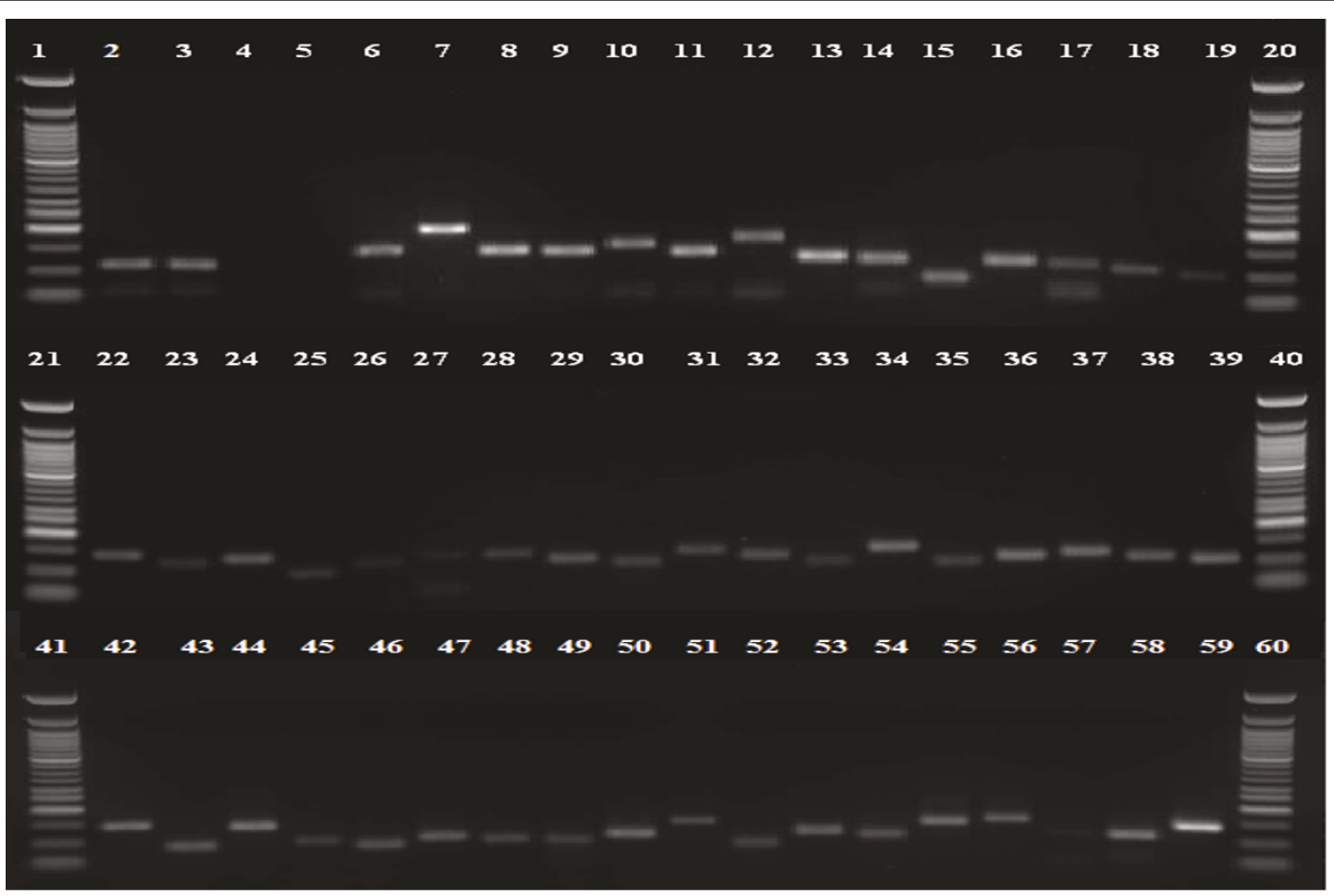

Figure $\mathbf{4}$ Experimental validation of $\mathbf{4 8}$ common bean $\mathbf{4 5 4}$-sequencing derived unigenes by RT-PCR. Lanes with 50 bp ladder are lanes 1 , 20, 21, 40, 41, and 60; Confirmation of absence of DNA contamination is shown in lanes 2-5 where RT-PCR amplification was carried out with primers designed from contig11286 in lanes with genomic DNA, leaf CDNA, leaf CDNA control (no reverse transcriptase added to reaction), and water as template to check DNA contamination. In lanes 6-19, 22-39, and 42-56, 58 and 59 RT-PCR products derived by amplification from an additional 47 common bean unigenes using leaf cDNA as a template are shown (complete list of contigs shown in Table 4 ). Lane 57 is amplification by the cons7 primers.

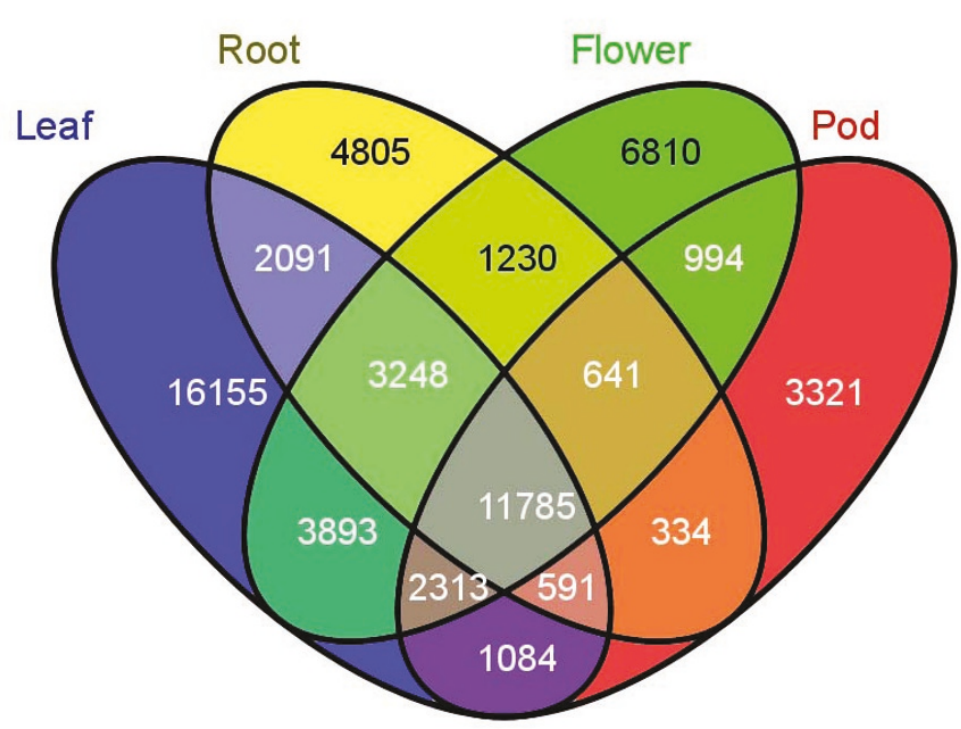

Figure 5 Tissue-specific expression of common bean unigenes. cDNA libraries were tagged during library construction; in the figure, blue represents transcripts present in leaves, yellow represents transcripts present in roots, green represents transcripts present in flower, and red represents transcripts present in pods. 
Table 4 Identification of tissue-specific unigenes from common bean 454 sequences

\begin{tabular}{cccc}
\hline Tissue-specific unigenes & No. of unigenes & Average reads & No. of reads in the largest contigs \\
\hline Leaf-specific & 16,155 & 1.99 & 96 \\
Root-specific & 4,805 & 2.21 & 502 \\
Pod-specific & 3,321 & 3.63 & 650 \\
Flower-specific & 6,810 & 1.87 & 231 \\
Mixed-tissue unigenes & 28,204 & 59.83 & 2,484 \\
All unigenes & 59,295 & 29.60 & 2,484 \\
\hline
\end{tabular}

interesting. The contigs and singletons which contain flower, root, and pod-specific transcripts will be very useful to understand and compare with transcriptomic sequences derived from other temporal and spatial conditions from other studies.

\section{SSR analysis}

Simple sequence repeats (SSRs), or microsatellites consist of repeats of short nucleotide motifs with two to six base pairs in length. In the present study, the 59,295 454-derived sequences from common bean (estimated length of $22.93 \mathrm{Mbp}$ ) and 92,124 common bean genomic sequences (validated September 2010; estimated length of $64.67 \mathrm{Mbp}$ ) were analyzed for SSR sequences using the software MISA http://pgrc.ipk-gatersleben.de/ misa. We surveyed these and all other sequences mentioned in this analysis for di-, tri-, tetra-, penta- and hexa-nucleotide type of SSRs. We detected a total of 1,516 and 4,517 SSRs in 454-derived and genomic sequences respectively (Table 5 ). In order to determine the identification of SSR sequences from other plants with both transcriptome and genomic resources, we analyzed 33,001 unigenes and 973.34 Mbp of genomic sequences from G. $\max , 18,098$ unigenes and 105.5 Mbp of genomic sequences from $M$. truncatula, and 30,579 unigenes and the whole genome from Arabidopsis. In G. max, we found 3,548 SSRs in the unigenes, and 143,666 SSRs in genomic sequences. In M. truncatula, we found 1,470 SSRs in the unigenes, and 10,412 SSRs in the genomic sequences, and finally we found
5,586 SSRs in Arabidopsis unigenes, and 14,110 SSRs in Arabidopsis genomic sequences (Table 5).

We then analyzed the average distance between any two SSRs and found that this differed among species. The average distance between two SSRs in unigenes and genomic sequences of $P$. vulgaris was $15.13 \mathrm{~kb}$ and $14.32 \mathrm{~kb}$ respectively, higher than that of the other three species. However, the average distance between two SSRs was quite similar between unigenes and genomic sequences for common bean, soybean, Medicago, and lotus (Table 5).

The frequency of SSRs in terms of repeat motif length (di-, tri-, tetra-, penta-, and hexa- nucleotide) was different. Of all the SSRs found in common bean unigenes, dinucleotide, trinucleotide, tetranucleotide, pentanucleotide and hexanucleotide repeats account for $36.15 \%$, $59.50 \%, 2.57 \%, 0.79 \%$, and $0.99 \%$, respectively, while repeats account for $70.02 \%, 26.85 \%, 2.17 \%, 0.51 \%$ and $0.44 \%$ in genomic sequences. In G. max unigenes, dinucleotide, trinucleotide, tetranucleotide, pentanucleotide and hexanucleotide repeats account for 42.64\%, 54.20\%, $2.00 \%, 0.51 \%$, and $0.65 \%$, respectively, and was $69.50 \%$, $26.74 \%, 2.75 \%, 0.81 \%$ and $0.20 \%$ in genomic sequences. In $M$. truncatula unigenes, dinucleotide, trinucleotide, tetranucleotide, pentanucleotide and hexanucleotide repeats account for $35.03 \%, 59.66 \%, 3.33 \%, 1.16 \%$, and $0.82 \%$, respectively, and was $62.06 \%, 33.92 \%, 3.02 \%$, $0.61 \%$ and $0.39 \%$ in genomic sequences. In Arabidopsis unigenes, dinucleotide, trinucleotide, tetranucleotide, pentanucleotide and hexanucleotide repeats account for

Table 5 SSR survey in unigenes and genomic sequences from $P$. vulgaris, G. max, M. truncatula, and $A$. thaliana.

\begin{tabular}{lcccccccc}
\hline Type & \multicolumn{2}{c}{$\boldsymbol{P}$. vulgaris } & \multicolumn{2}{c}{ G. max } & \multicolumn{2}{c}{ M. truncatula } & \multicolumn{2}{c}{ A. thaliana } \\
\cline { 2 - 8 } & Unigene & Genome & Unigene & Genome & Unigene & Genome & Unigene & Genome \\
\hline Dinucleotide & 548 & 3163 & 5944 & 99856 & 1903 & 6462 & 1914 & 8686 \\
Trinucleotide & 902 & 1213 & 5771 & 38411 & 2999 & 3532 & 3600 & 5180 \\
Tetranucleotide & 39 & 98 & 238 & 3954 & 165 & 314 & 34 & 155 \\
Pentanucleotide & 12 & 23 & 66 & 1161 & 53 & 63 & 8 & 38 \\
Hexanucleotide & 15 & 20 & 100 & 284 & 65 & 41 & 30 & 51 \\
Total SSR & 1516 & 4517 & 12119 & 143666 & 5158 & 10412 & 5586 & 14110 \\
Total length (Mbp) & 22.94 & 64.68 & 71.80 & 973.34 & 51.93 & 105.52 & 43.58 & 111.14 \\
Average distance $(\mathrm{kb})$ & 15.13 & 14.32 & 5.92 & 6.78 & 10.07 & 10.13 & 7.80 & 7.88 \\
\hline
\end{tabular}


$34.26 \%, 64.45 \%, 0.61 \%, 0.14 \%$, and $0.54 \%$, respectively, which was different from $61.56 \%, 36.71 \%, 1.10 \%, 0.27 \%$ and $0.36 \%$ in genomic sequences. The most frequent type of repeat motif between unigenes and genomic sequences was different. Trinucleotide SSRs were the most common type in unigenes in all the four species, while dinucleotide SSRs were the most common type in genomic sequences. These EST-SSRs will help to develop SSR markers with high polymorphism for common bean.

Tri-nucleotides were found to be the most abundant repeats and AAG/CTT repeats were the most frequent motifs in the tri-nucleotides. The prevalence of trinucleotide over di-nucleotide or other SSRs was also observed in the unigenes of G. max, M. truncatula and A. thaliana, and also may be characteristic of EST-SSRs of maize, wheat, rice, sorghum, barley [28] and many other plant species $[29,30]$. In contrast, di-nucleotides were the most common repeats in the genomic sequences of the four species and AT/AT was the most dominant repeat. Blair et al. [30,31] and Cordoba et al. [32] identified 184 gene-based SSRs and 875 SSRs from common bean ESTs and BAC-end sequences, respectively. They also found that tri-nucleotide SSRs were more common in ESTs, while di-nucleotide SSRs were more dominant in GSSs. The frequency of SSR-containing ESTs in the common bean unigenes as shown in this study was $2.37 \%$ and much lower than that of rice [28], bread wheat [33], and other plants [29]. The SSRs identified in the present study can be used by the common bean community as molecular markers for mapping of important agronomic traits and for integration of common bean genetic and physical maps.

\section{Validation of selected bean 454 transcripts}

We wanted to verify the expression of common bean ESTs identified in this work, before which we ensured that the procedures that we were following in the laboratory were consistent and that there was no contamination of the cDNA with genomic DNA. Figures $6 \mathrm{~A}$ and $6 \mathrm{~B}$ show that the cDNA that we have used for our gene expression experiments is contamination free. We wanted to test the accuracy of the contigs assembled by the gsAssembler with reverse transcriptase (RT)-PCR. We designed PCR primers for 48 randomly selected contigs (Table 6) and analyzed the cDNA under standard PCR conditions and electrophoresed the products on a $2 \%$ agarose gel (Figure 4 ).

Almost all of the amplifications yielded single products ranging from $100 \mathrm{bp}-150 \mathrm{bp}$ showing that these are real transcripts derived from mRNA.

\section{Quantitative PCR analysis of 23 common bean contigs}

Of the 48 contigs whose amplification is shown in Figure 4, we randomly chose 23 contigs (Table 7 ) for further analysis with quantitative PCR. Randomly selected contigs were tested to determine if they were derived from RNA sequences and for their expression pattern in common bean plant parts under ambient conditions. Relative quantification of contig expression was performed by comparative $\Delta \Delta \mathrm{C}_{\mathrm{T}}$ analysis from leaf, flower, pod and root tissues using leaf as a reference sample.

\section{A}

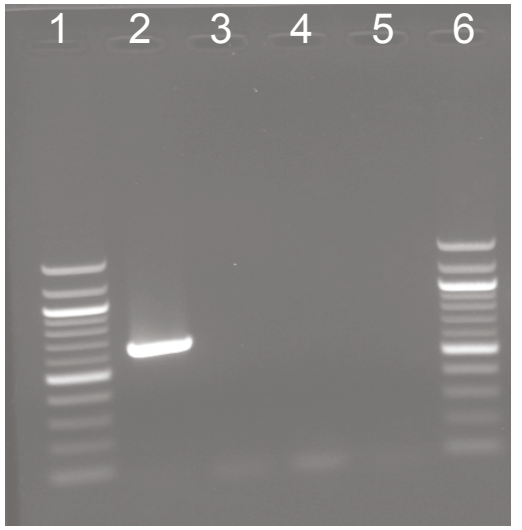

\section{B}

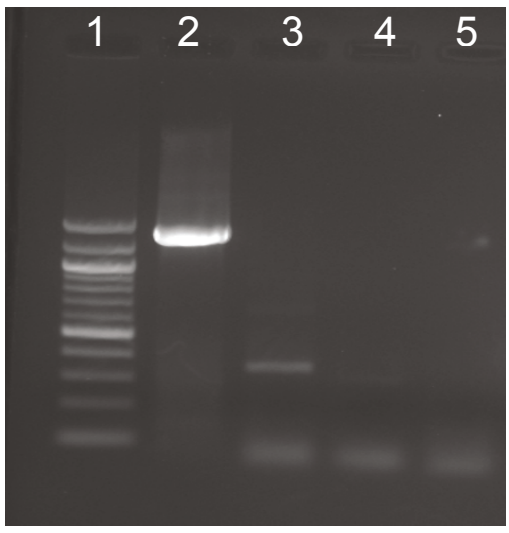

Figure 6 Tests for DNA contamination in reverse transcriptase PCR. (A) Common bean sequence characterized amplified repeat (SCAR) marker SK14, linked to the Ur-3 rust resistance locus. From our experiments, SK14 amplifies from genomic DNA but not from cDNA, presumably because SK14 is from the intronic region of the gene. Forward and reverse primers derived from the SK14 sequence were used to amplify a 600 bp product from genomic DNA and CDNA; no amplification from cDNA was observed. Lane 1, 100 bp ladder; Lane 2, genomic DNA; Lane 3, leaf cDNA; Lane 4. Negative cDNA control (no reverse transcriptase was added to cDNA synthesis reaction); Lane 5, $\mathrm{H}_{2} \mathrm{O}$ only control; Lane 6, 100 bp ladder. (B) Primers from contig32565, a sequence with homology to a MADS transcription factor amplified long flanking intronic genomic DNA yielding a $1200 \mathrm{bp}$ amplicon from genomic DNA and a short $300 \mathrm{bp}$ amplicon from cDNA. The order and contents of lanes 1 to 5 are identical to those in panel $\mathrm{A}$. 
Table 6 Description of unigenes randomly selected for validation

\begin{tabular}{|c|c|c|}
\hline Lane No. & Unigene Name & Annotation \\
\hline 2 & contig11286 & MLO8 (MILDEW RESISTANCE LOCUS O 8); calmodulin binding [Arabidopsis thaliana] \\
\hline 3 & contig11286 & MLO8 (MILDEW RESISTANCE LOCUS O 8); calmodulin binding [Arabidopsis thaliana] \\
\hline 4 & contig11286 & MLO8 (MILDEW RESISTANCE LOCUS O 8); calmodulin binding [Arabidopsis thaliana] \\
\hline 5 & contig11286 & MLO8 (MILDEW RESISTANCE LOCUS O 8); calmodulin binding [Arabidopsis thaliana] \\
\hline 6 & contig33974 & MLO1 [Lotus corniculatus var. japonicus] \\
\hline 7 & contig32923 & ATMLO1/MLO1 (MILDEW RESISTANCE LOCUS O 1); calmodulin binding [Arabidopsis thaliana] \\
\hline 8 & contig01942 & resistance gene analog NBS1 [Helianthus annuus] \\
\hline 9 & contig04562 & R 10 protein [Glycine max] \\
\hline 10 & contig05928 & MLO1 [Lotus corniculatus var. japonicus] \\
\hline 11 & contig28775 & L6-like resistance gene \\
\hline 12 & contig35803 & Mlo-like resistance gene \\
\hline 13 & contig36500 & Hm1-like resistance gene \\
\hline 14 & contig39371 & $\mathrm{N}$-like resistance gene \\
\hline 15 & FFSTDNT01C34EJ & Fls2-like resistance gene \\
\hline 16 & FGQI37401AS3FB & Pto-like kinase OG10 [Phaseolus vulgaris] \\
\hline 17 & contig29749 & Phaseolin \\
\hline 18 & contig38383 & fructokinase-like protein [Cicer arietinum] \\
\hline 19 & contig04711 & alcohol dehydrogenase [Prunus armeniaca] \\
\hline 22 & contig20010 & ABC transporter family protein [Arabidopsis thaliana] \\
\hline 23 & contig 14749 & senescence-associated nodulin 1A [Glycine max] \\
\hline 24 & contig28207 & Late embryogenesis abundant protein Lea14-A, putative [Ricinus communis] \\
\hline 25 & contig07734 & phosphoenolpyruvate carboxylase kinase [Glycine max] \\
\hline 26 & contig 28742 & fructokinase-like protein [Cicer arietinum] \\
\hline 27 & contig33251 & sucrose synthase [Vigna angularis] \\
\hline 28 & contig38427 & senescence-associated nodulin 1A [Glycine max] \\
\hline 29 & contig28548 & nodulin-26 \\
\hline 30 & contig08830 & WRKY35 [Glycine max] \\
\hline 31 & contig14217 & NAC domain protein NAC1 [Phaseolus vulgaris] \\
\hline 32 & contig32665 & transcriptional factor NAC11 [Glycine max] \\
\hline 33 & contig17174 & dihydroflavonol-4-reductase 2 [Glycine max] \\
\hline 34 & contig29672 & glutathione S-transferase GST 19 [G/ycine max] \\
\hline 35 & contig13083 & 4-hydroxyphenylpyruvate dioxygenase [Glycine max] \\
\hline 36 & contig32781 & WRKY23 [Glycine max] \\
\hline 37 & contig30192 & WRKY54 [Glycine max] \\
\hline 38 & contig05219 & zinc finger (CCCH-type) family protein [Arabidopsis thaliana] \\
\hline 39 & contig35898 & bZIP transcription factor bZIP80 [Glycine max $]$ \\
\hline 42 & contig12172 & WRKY9 [Glycine max] \\
\hline 43 & contig34970 & MYB transcription factor MYB57 [Glycine max] \\
\hline 44 & contig29192 & MYB transcription factor MYB183 [Glycine max] \\
\hline 45 & contig29047 & GAMYB-binding protein [Glycine max] \\
\hline 46 & contig07725 & MYB transcription factor MYB150 [Glycine max] \\
\hline 47 & contig27846 & MYB transcription factor MYB57 [Glycine max] \\
\hline 48 & contig02140 & MYB transcription factor MYB93 [Glycine max] \\
\hline 49 & contig04868 & flavonoid 3'-hydroxylase [Glycine max] \\
\hline 50 & contig00375 & flavonoid 3-O-galactosyl transferase [Vigna mungo] \\
\hline 51 & contig35817 & microsomal omega- 6 fatty acid desaturase [Glycine max] \\
\hline 52 & contig17418 & omega-3 fatty acid desaturase [Vigna unguiculata] \\
\hline 53 & contig08522 & (iso)flavonoid glycosyltransferase [Medicago truncatula] \\
\hline 54 & contig09139 & enoyl-ACP reductase [Malus $x$ domestica] \\
\hline 55 & contig10732 & peroxisomal fatty acid beta-oxidation multifunctional protein [Glycine max] \\
\hline 56 & contig33363 & beta-ketoacyl-CoA synthase family protein [Arabidopsis thaliana] \\
\hline
\end{tabular}


Table 6 Description of unigenes randomly selected for validation (Continued)

\begin{tabular}{lll}
\hline 57 & cons7 & reference gene \\
58 & contig11286 & MLO8 (MILDEW RESISTANCE LOCUS O 8); calmodulin binding [Arabidopsis thaliana] \\
59 & contig33974 & MLO1 [Lotus corniculatus var. japonicus] \\
\hline
\end{tabular}

Table 7 Expression analysis of common bean contigs

\begin{tabular}{|c|c|c|c|c|c|}
\hline \multirow{2}{*}{$\begin{array}{l}454 \text { Contig } \\
\text { Number }\end{array}$} & \multicolumn{3}{|c|}{$2^{-\Delta \Delta C T}$ Values } & \multirow[t]{2}{*}{ Functional Annotation } & \multirow[t]{2}{*}{ Primer Sequences } \\
\hline & Flower & Pod & Root & & \\
\hline contig04711 & $3.43 \pm 0.04$ & $-2.20 \pm 0.09$ & $-0.82 \pm 0.26$ & Alcohol dehydrogenase [Prunus armeniaca] & $\begin{array}{l}\text { 5'-ATA TGC CTC TGT CTT GGC AGG AGT-3' } \\
\text { 5'-ACC TCG GGC AAT AGC ATT GAC TCT-3' }\end{array}$ \\
\hline contig07734 & $2.16 \pm 0.19$ & $1.52 \pm 0.07$ & $-0.45 \pm 0.1$ & $\begin{array}{l}\text { Phosphoenolpyruvate carboxylase kinase } \\
\text { [Glycine max] }\end{array}$ & $\begin{array}{l}\text { 5'-AGA ATG TGC GAA ACG CTG AAG ACG-3' } \\
\text { 5'-AGG ATG GAA ACA CCG GAA GAT GGT-3' }\end{array}$ \\
\hline contig08043 & $3.78 \pm 0.18$ & $-1.46 \pm 0.17$ & $-0.28 \pm 0.18$ & Starch synthase III [Phaseolus vulgaris] & $\begin{array}{l}\text { 5'-AAG AAC TTG CTA GGG TGC AAG CTG-3' } \\
\text { 5'-CTT TGC AGC TCT GTC TGC CTC AAT-3' }\end{array}$ \\
\hline contig08830 & $-5.22 \pm 0.14$ & $6.91 \pm 0.17$ & $-1.24 \pm 0.04$ & WRKY35 [Glycine max] & $\begin{array}{l}\text { 5'-TCA GCC TTG ACC TTG GTA TGG GAA-3' } \\
\text { 5'-TTG CTG GTA TGA GCT TGG CTG TCA-3' }\end{array}$ \\
\hline contig01300 & * & $-10.28 \pm 0.07$ & $1.32 \pm 0.26$ & $\begin{array}{l}\text { MADS box protein SEP3 [Lotus corniculatus } \\
\text { var. japonicus] }\end{array}$ & $\begin{array}{l}\text { 5'-AAT TGC TCA TGC TTG GAC CTG CTG-3' } \\
\text { 5'-TGA AGA CAT GGG ATA TGG CAG GCA-3' }\end{array}$ \\
\hline contig13083 & $-0.69 \pm 0.17$ & $2.55 \pm 0.12$ & $1.49 \pm 0.11$ & $\begin{array}{l}\text { 4-hydroxyphenylpyruvate dioxygenase [Glycine } \\
\max ]\end{array}$ & $\begin{array}{l}\text { 5'-TTA TGC CAA CCT TCA CAA GCG TGC-3' } \\
\text { 5'-TGC CCT GAT CGT CTC TGT CAA CAA-3' }\end{array}$ \\
\hline contig14749 & $6.66 \pm 0.08$ & $0.17 \pm 0.09$ & $3.07 \pm 0.27$ & $\begin{array}{l}\text { Senescence-associated nodulin 1A [Glycine } \\
\max ]\end{array}$ & $\begin{array}{l}5^{\prime}-\pi T C \text { TTC TC CCT GCA CAC GAC ACT-3' } \\
5^{\prime}-T T G \text { CTG CCC TाT CTA CGG ACA AGA-3' }\end{array}$ \\
\hline contig 17174 & $-1.41 \pm 0.24$ & $-6.58 \pm 0.07$ & $3.63 \pm 0.12$ & Dihydroflavonol-4-reductase 2 [Glycine max] & $\begin{array}{l}\text { 5'-TGG TAG CCT CAT GCG AAC AGC ATA-3' } \\
\text { 5'-AGG CCA GTT CGT GCA CTT AGA TGA-3' }\end{array}$ \\
\hline contig14217 & $-1.88 \pm 0.14$ & $9.86 \pm 0.1$ & $1.15 \pm 0.04$ & $\begin{array}{l}\text { NAC domain protein NAC1 [Phaseolus } \\
\text { vulgaris] }\end{array}$ & $\begin{array}{l}\text { 5'-TGG GTG CCC TTC CTT GAT AGA ACA-3' } \\
5^{\prime} \text {-TGC AAC AGG GTT ACG CAC AAA TCG-3' }\end{array}$ \\
\hline contig20010 & $6.07 \pm 0.05$ & $0.36 \pm 0.08$ & $1.34 \pm 0.27$ & $\begin{array}{l}\text { ABC transporter family protein [Arabidopsis } \\
\text { thaliana] }\end{array}$ & $\begin{array}{l}\text { 5'-ACA ACC TाT GTT TCA GCA CGG AGC-3' } \\
\text { 5'-GAG ACA TGG GCA ACT CAT TTG GCA-3' }\end{array}$ \\
\hline contig28207 & $1.40 \pm 0.19$ & $-2.44 \pm 0.12$ & $-2.38 \pm 0.1$ & $\begin{array}{l}\text { Late embryogenesis abundant protein Lea14- } \\
\text { A, putative [Ricinus communis] }\end{array}$ & $\begin{array}{l}\text { 5'-TGA CAG TCT GTT CTC CGT GTG CAT-3' } \\
\text { 5'-TAA AGA ACC CAA ATC CGG TGC CGA-3' }\end{array}$ \\
\hline contig28548 & $*$ & $-1.99 \pm 0.06$ & $-0.33 \pm 0.1$ & nodulin-26 & $\begin{array}{l}\text { 5'-TTG GTC CAG GTC CAG CTA ACA ACA-3' } \\
\text { 5'-CCC ATC GCC ATT GGT TTC ATC GTT-3' }\end{array}$ \\
\hline contig29672 & $1.51 \pm 0.24$ & $3.16 \pm 0.11$ & $1.01 \pm 0.07$ & glutathione S-transferase GST 19 [Glycine max] & $\begin{array}{l}\text { 5'-AGC TCT TCA AGG ACA CTG AGC CAA-3' } \\
\text { 5'-AAA GGC TGT GGA TGC TGC ACT AGA-3' }\end{array}$ \\
\hline contig28742 & $-0.84 \pm 0.21$ & $-6.13 \pm 0.07$ & $-4.19 \pm 0.1$ & Fructokinase-like protein [Cicer arietinum] & $\begin{array}{l}\text { 5'-TGA GTA TाT GCT GAC GCG CTा CCT-3' } \\
\text { 5'-GCA CAC CTG AAG GCA ATG GAA GTT-3' }\end{array}$ \\
\hline contig28845 & $-0.98 \pm .014$ & $0.51 \pm 0.1$ & $-2.96 \pm 0.04$ & NAC domain protein [Glycine max] & $\begin{array}{l}\text { 5'-TGG TGT GGT CCT GCA GAG TGT AAA-3' } \\
\text { 5'-AAC GTC GGT GAT TGG GAG GAG AAA-3' }\end{array}$ \\
\hline contig28932 & $4.83 \pm 0.24$ & $4.73 \pm 0.07$ & $3.81 \pm 0.07$ & $\begin{array}{l}\text { Nodule-enhanced protein phosphatase type } \\
2 C \text { [Lotus japonicus] }\end{array}$ & $\begin{array}{l}\text { 5'-AAC GTC GGT GAT TGG GAG GAG AAA-3' } \\
\text { 5'-CTT GCT GCT TCG CTT TGT CAC TGT-3' }\end{array}$ \\
\hline contig28932 & $-4.04 \pm 0.16$ & $7.80 \pm 0.12$ & $-5.34 \pm 0.12$ & $\begin{array}{l}\text { nodule-enhanced protein phosphatase type } \\
\text { 2C [Lotus japonicus] }\end{array}$ & $\begin{array}{l}\text { 5'-AAC GTC GGT GAT TGG GAG GAG AAA-3' } \\
\text { 5'-ATC CCT CTC TCC TTC GCA GCA AAT-3' }\end{array}$ \\
\hline contig30192 & $1.61 \pm 0.22$ & * & $0.58 \pm 0.11$ & WRKY54 [Glycine max] & $\begin{array}{l}\text { 5'CAA CAC ACA CAT CCA AGC CCA GTT3' } \\
\text { 5'GG TTC TGC TGC TGC TGA TAC TGT3' }\end{array}$ \\
\hline contig30958 & $1.17 \pm 0.15$ & $11.91 \pm 0.11$ & $3.89 \pm 0.08$ & WRKY27 [Glycine max] & $\begin{array}{l}\text { 5'ACG GAA ACT CTG AGA GCA GCT CAA3' } \\
\text { 5' TGC TTC CGT CCT CAC GTA AAC TCT3' }\end{array}$ \\
\hline contig32565 & $-8.41 \pm 0.15$ & $-10.63 \pm 0.11$ & $0.90 \pm 0.37$ & MADS transcription factor [Glycine max] & $\begin{array}{l}\text { 5'-TGC CTC ACC TAG CAA GTG TTC CTT-3' } \\
5^{\prime} \text {-AGA TCT TGG CCC TCT AAG CAG CAA-3' }\end{array}$ \\
\hline contig32665 & $1.26 \pm 0.24$ & $4.39 \pm 0.09$ & $0.33 \pm 0.07$ & Transcriptional factor NAC11 [Glycine max] & $\begin{array}{l}\text { 5'-AAT GTG GTC TGA GGA GGT GGT GTT-3' } \\
\text { 5'-ATG CTC TAA CTT CAG CGG AGG CAA-3' }\end{array}$ \\
\hline contig32781 & $1.33 \pm 0.17$ & $1.82 \pm 0.12$ & $-2.89 \pm 0.12$ & WRKY23 [Glycine max] & $\begin{array}{l}\text { 5'GCA TGT TGC TGT CAG GGT CAA TGT3' } \\
\text { 5'GG TGC TGA AGC TGA AAG TGT TGC3' }\end{array}$ \\
\hline contig33251 & $-0.09 \pm .019$ & $-3.93 \pm 0.06$ & $-4.10 \pm 0.1$ & Sucrose synthase [Vigna angularis] & $\begin{array}{l}\text { 5'-ACG GCT AGT TTC CTT GTG GGA GAA-3' } \\
5^{\prime}-\mathrm{TCT} \text { CAC ACA GCT TTC ACC CTT CCT-3' }\end{array}$ \\
\hline
\end{tabular}


Almost all of the contigs showed expression as illustrated in Table 7 . We highlight a few contigs here including contig28742 (fructose-like protein), contig2884 (NAC domain protein), contig33251 (sucrose synthase) and contig04711 (alcohol dehydrogenase) for which the expression levels were lower in flowers, pods and roots compared to leaves. Contig29672 (glutathione S-tranferase GST 19), contig28932 (noduleenhanced protein phosphatase type C), contig30958 (WRKY27), and contig38427 (senescence-associated nodulin 1A) showed higher expression levels in flower, pod and roots compared to leaves. Expression levels of contig30958 with homology to a WRKY-27 transcription factor involved in bacterial wilt resistance [34] and contig08830 with homology to another WRKY35 transcription factor were high (119-fold) in pods compared to leaves. Expression levels of contig14749 (senescence-associated nodulin 1A), contig20010 (ABC transporter family protein) and contig38383 (fructokinase-like protein) were higher (64 fold) in flower than leaf, pods, and roots. Interestingly PCR primers designed from contig32565 showed a size difference when amplified from genomic and cDNA, and it is possible that the primers were designed from a region flanking an intron (example shown in Figure 6B).

\section{Identification of transcription factors}

Putative common bean transcription factors (TFs) were identified by comparing Arabidopsis transcription factors http://plntfdb.bio.uni-potsdam.de/v3.0/ against the 454 sequencing-derived unigenes in this study [35]. A total of 2,516 unigenes coding for putative transcription factors were identified in common bean, which is similar to the 2,758 transcription factors discovered in Arabidopsis. However, these numbers represent about half of the transcription factors $(5,671)$ discovered in soybean. In Table 8 we show the 16 most common transcription factor families found in common bean and corresponding TFs identified from Arabidopsis [35] and soybean [36].

The largest share of common bean transcription factors (169) shows homology to the MYB super family similar to soybean (586) and Arabidopsis thaliana (266) which show the same abundance. This high number of MYB transcription factor identification may be due to their abundance in the genome as well as identification and characterization in model organisms. MYB genes are involved in regulation of various metabolic pathways and developmental regulation by determining cell fate and identity $[37,38]$. Study of these genes in common bean will help in the identification and analysis of important developmental pathways.

The second largest TF family in common bean (77) has similarity with the (NAM, ATAF1, 2 and CUC2) family as compared to 205 in soybean and 126 in Arabidopsis thaliana as shown in Table 8 . The NAC gene family is reported to be composed of plant-specific transcription factors with a broad role in plant development (especially in lignocelluloses and cell wall development) and response to external stimuli [39]. Several NAC genes were induced by cold and dehydration in Brassica napus [40], by abscisic acid (ABA) and salt stress in rice [41], drought and developmental processes in chickpea [42], salinity and osmotic stress [43] and stripe rust in wheat [44].

Table 8 Comparison of most common transcription factor families among common bean, soybean, and Arabidopsis derived by screening of the $P$. vulgaris 454 unigenes set against Arabidopsis transcription factors

\begin{tabular}{ccccc}
\hline Number & TF family & Number in P. vulgaris unigenes & Number in G. max & Number in Arabidopsis \\
\hline 1 & MYB & 169 & 586 & 266 \\
2 & NAC & 77 & 205 & 126 \\
3 & bHLH & 75 & 390 & 177 \\
4 & WRKY & 71 & 219 & 88 \\
5 & HB & 68 & 279 & 109 \\
6 & ARF & 67 & 75 & 24 \\
7 & AUX/IAA & 61 & 97 & 36 \\
8 & FAR1 & 59 & 0 & 24 \\
9 & CCCH & 58 & 176 & 85 \\
10 & PHD & 50 & 288 & 59 \\
11 & Ap2/EREBP & 48 & 405 & 168 \\
12 & bZIP & 48 & 191 & 111 \\
13 & SET & 44 & 0 & 46 \\
14 & mTERF & 40 & 0 & 36 \\
15 & SNF2 & 32 & 0 & 132 \\
16 & MADS box & 32 & 220 &
\end{tabular}


We found 44 SET, 40 mTERF, 32 SNF2 and 59 FAR1 unigenes in our study from common bean. There are 46 SET, 36 mTERF, 45 SNF2 and 24 FAR1 transcription factors from Arabidopsis which are not represented in the soybean and Medicago transcription factor databases http://bioinfo3.noble.org/dmtr/ to date. The SET TF family is involved in methylation of lysine residues on histone tails. As of now the SET family has been found only in a few species http://plntfdb.bio.uni-potsdam.de/ $\mathrm{v} 3.0 /$. It is important to reveal the structural and functional details of these transcription factors as studies on epigenetics are expanding [45]. The SNF2 family of proteins which are DNA-dependent ATPases play an important role in chromatin remodelling complexes that are involved in epigenetic gene regulation. The mTERF family contains leucine zipper-like heptads that may be involved in mtDNA transcription and replication [46] while the FAR1 family is involved in regulation of the circadian clock in Arabidopsis [47].

\section{Identification and analysis of nodulation-specific contigs in} the unigene dataset

The 52 soybean nodulation genes discovered by Schmutz et al. [48] were compared to the common bean unigenes, using the TBLASTN algorithm. We considered as orthologs, hits with an E-value of $<1 \times 10^{-20}$ as per McClean et al. (22). A total of 67 hits were identified and the average E-value for these hits was $3.3 \times$ $10^{-69}$ (Table 9). Sixteen unigenes are seen to be expressed more abundantly in root tissues and this gene family will be investigated in further detail in subsequent studies.

\section{Conclusions}

Genomic resources in legume crops are lacking with the exception of soybean and Medicago for which wholegenome sequences are now available. Since the common bean genome is relatively small compared to other legumes, there is a great potential to utilize and apply the information from common bean to other legume crops such as soybean, cowpea, mung bean, rice bean and lentils. We have partially made up for this lack of genomic information by sequencing a large number of cDNAs. In summary, we identified 59,295 common bean unigenes of which 31,664 unigenes are newly discovered sequences. Combined with existing transcriptomic and genomic sequences available for common bean, this dataset will be very useful for functional genomics research in common bean.

Comparison of the number of common bean unigene matches to other legumes shows that there may be many more legume unigenes that are yet to be discovered. Therefore, high throughput transcriptome sequencing will continue to help in identifying genes associated with biotic and abiotic stress, development of high resolution genetic maps, and automated phenotyping which will lead to crop improvement.

\section{Methods}

\section{Plant materials}

Common bean plants were grown in the greenhouse and leaves, flowers, and root tissues (from common bean cultivar Sierra) and pods (from common bean genotype BAT93) were collected into envelopes and frozen in liquid nitrogen for further processing.

\section{RNA isolation, cDNA synthesis and normalization}

Total RNA was extracted from the four tissues using Plant RNA Reagents (Invitrogen; Carlsbad, CA). mRNAs (PolyA RNA) were isolated by using Oligotex Mini Kit (Qiagen; Valencia, CA). cDNA was synthesized from $500 \mathrm{ng}$ of mRNA following Clontech's (Mountain View, CA) Creator SMART cDNA synthesis system using modified Oligo-dT (to make compatible with 454 GS FLX) and 5' RACE primers. The primer sequences are: CDSIII-First 454: 5’ TAG AGA CCG AGG CGG CCG ACA TGT TTT GTT TTT TTT TCT TTT TTT TTT VN 3' and SMARTIV: 5' AAG CAG TGG TAT CAA CGC AGA GTG GCC ATT ACG GCC GGG 3'.

For normalization, 300 nanograms (ng) of cDNA was denatured and allowed to self-anneal in a $1 \times$ hybridization buffer ( $50 \mathrm{mM}$ Hepes, $\mathrm{pH} 7.5$ and $0.5 \mathrm{M} \mathrm{NaCl}$ ) for a period of $4 \mathrm{hrs}$. Within this hybridization period, most of the abundant transcripts found their homologs to form double stranded (ds) molecules but the unique/ rare transcripts and their homologs remain as single stranded (ss). After hybridization, duplex/double stranded specific Nuclease-DSN (Evrogen, Russia) was added to the reaction to degrade ds-cDNAs. Single stranded transcripts and their homologs that remained in the treated reactions were PCR amplified to make normalized ds-cDNA.

\section{Library preparation (DNA processing) for 454 (GSFLX) sequencing}

cDNA was nebulized and size selected for an average size of 400-500 bp. 454 GSFLX specific adapters, Adapter A and AdapterB, with $10 \mathrm{bp}$ MIDs in AdapterA were ligated to the cDNA ends after end-polishing reaction. The adapter ligated DNAs were then mobilized to the library preparation beads and ss-cDNAs were captured. Number of molecules of the ss-cDNAs was calculated using the concentration and average fragment length.

\section{emPCR, Enrichment and DNA Bead Loading}

Emulsion PCR (emPCR) reactions were set up for titration run using $6 \times 10^{5}, 2.4 \times 10^{6}, 4.8 \times 10^{6}$ and $9.6 \times$ $10^{6}$ molecules of ss-cDNAs that corresponds to $0.5,2,4$ and 8 copies, respectively, of the ss-cDNA per bead. 
Table 9 Analysis of tentative nodulation genes from 454 unigenes of common bean

\begin{tabular}{|c|c|c|c|c|c|c|c|}
\hline \multirow[t]{2}{*}{ unigenes } & \multirow[t]{2}{*}{ matched soybean sequences } & \multirow[t]{2}{*}{ score } & \multirow[t]{2}{*}{ E-value } & \multicolumn{4}{|c|}{454 sequencing reads } \\
\hline & & & & leaf & root & Pod & flower \\
\hline contig34312 & Glyma01g03470.1/N36a & 440 & $3.00 \mathrm{E}-124$ & 40 & 24 & 26 & 63 \\
\hline contig34712 & Glyma01g03470.1/N36a & 181 & 4.00E-46 & 1 & 9 & 12 & 9 \\
\hline contig04894 & Glyma02g43860.1 & 499 & $5.00 \mathrm{E}-142$ & 42 & 69 & 35 & 4 \\
\hline FFODN3U02HB71T & Glyma02g43860.1 & 119 & $5.00 \mathrm{E}-29$ & 0 & 1 & 0 & 0 \\
\hline contig27995 & Glyma04g00210.1 & 196 & $1.00 \mathrm{E}-50$ & 1 & 4 & 0 & 1 \\
\hline contig37370 & Glyma05g250100.1/Nodulin-21 & 116 & $3.00 \mathrm{E}-27$ & 6 & 1 & 1 & 0 \\
\hline contig06012 & Glyma07g33070.1/SAN1B & 430 & $2.00 \mathrm{E}-121$ & 61 & 5 & 6 & 2 \\
\hline contig14749 & Glyma07g33070.1/SAN1B & 463 & $3.00 \mathrm{E}-131$ & 17 & 1 & 7 & 4 \\
\hline contig38427 & Glyma07g33070.1/SAN1B & 607 & 7.00E-175 & 83 & 0 & 13 & 0 \\
\hline FGQI37402G5N7N & Glyma07g33070.1/SAN1B & 117 & $1.00 \mathrm{E}-28$ & 0 & 1 & 0 & 0 \\
\hline contig06610 & Glyma07g33090.1/SAN1A & 128 & $1.00 \mathrm{E}-30$ & 0 & 25 & 0 & 0 \\
\hline contig31277 & Glyma07g33090.1/SAN1A & 409 & $5.00 \mathrm{E}-115$ & 32 & 30 & 15 & 24 \\
\hline FF0DN3U02F89J3 & Glyma07g33090.1/SAN1A & 89 & $6.00 \mathrm{E}-20$ & 0 & 1 & 0 & 0 \\
\hline contig07549 & Glyma08g05370.1 & 328 & $2.00 \mathrm{E}-90$ & 12 & 29 & 16 & 1 \\
\hline contig28119 & Glyma08g05370.1 & 191 & $6.00 E-49$ & 0 & 8 & 3 & 2 \\
\hline contig30228 & Glyma08g05370.1 & 279 & $2.00 \mathrm{E}-75$ & 62 & 22 & 33 & 5 \\
\hline FF0DN3U02G2ENE & Glyma08g05370.1 & 117 & $2.00 \mathrm{E}-28$ & 1 & 0 & 0 & 0 \\
\hline contig14951 & Glyma08g12650.1/Nodulin-26a & 351 & $1.0 \mathrm{E}-97$ & 102 & 11 & 49 & 20 \\
\hline contig19563 & Glyma08g12650.1/Nodulin-26a & 119 & $7.00 \mathrm{E}-28$ & 0 & 3 & 0 & 2 \\
\hline contig33328 & Glyma09g33510.1/NORK & 202 & $1.00 \mathrm{E}-53$ & 0 & 56 & 13 & 0 \\
\hline contig05955 & Glyma10g06610.1 & 395 & $3.00 \mathrm{E}-110$ & 18 & 3 & 64 & 18 \\
\hline contig16149 & Glyma10g06610.1 & 164 & $1.00 \mathrm{E}-40$ & 19 & 1 & 45 & 43 \\
\hline FFSTDNT01DSPY6 & Glyma10g06610.1 & 138 & $7.00 \mathrm{E}-35$ & 0 & 1 & 0 & 0 \\
\hline contig05559 & Glyma10g23790.1/Nod35 & 584 & $6.00 \mathrm{E}-168$ & 54 & 25 & 13 & 33 \\
\hline contig35956 & Glyma10g39450.1/Nodulin-33 & 251 & 7.00E-68 & 109 & 44 & 42 & 6 \\
\hline contig36020 & Glyma10g39450.1/Nodulin-33 & 450 & $1.00 \mathrm{E}-127$ & 6 & 27 & 21 & 195 \\
\hline contig14075 & Glyma11g06740.1 & 148 & $2.00 \mathrm{E}-36$ & 0 & 3 & 0 & 0 \\
\hline contig37552 & Glyma11g09330.1 & 178 & $2.00 E-45$ & 5 & 0 & 53 & 122 \\
\hline FF0DN3U01DKJ7W & Glyma1 1g09330.2 & 92.4 & $7.00 \mathrm{E}-21$ & 4 & 0 & 00 & \\
\hline contig29881 & Glyma12g04390.1/GmNARK & 428 & $3.00 \mathrm{E}-120$ & 24 & 15 & 34 & 4 \\
\hline contig38136 & Glyma12g04390.1/GmNARK & 387 & 7.00E-108 & 205 & 193 & 377 & 122 \\
\hline FGQ137401COXA9 & Glyma12g04390.1/GmNARK & 100 & 4.00E-23 & 0 & 0 & 1 & 0 \\
\hline contig06199 & Glyma12g05390.1 & 284 & 5.00E-77 & 15 & 2 & 1 & 0 \\
\hline FFSTDNT01A6UXI & Glyma12g05390.1 & 111 & $2.00 \mathrm{E}-26$ & 0 & 0 & 1 & 0 \\
\hline contig11587 & Glyma12g28860.1 & 143 & $1.00 \mathrm{E}-34$ & 2 & 0 & 1 & 0 \\
\hline contig33251 & Glyma13g17420.1/Nod100 & 447 & $5.00 \mathrm{E}-126$ & 8 & 14 & 27 & 58 \\
\hline contig36251 & Glyma13g17420.1/Nod100 & 344 & 3.00E-95 & 19 & 10 & 14 & 21 \\
\hline contig36660 & Glyma13g17420.1/Nod100 & 358 & 2.00E-99 & 11 & 10 & 27 & 119 \\
\hline FFSTDNTO1BOZRN & Glyma13g17420.1/Nod100 & 113 & $2.00 \mathrm{E}-27$ & 0 & 1 & 0 & 0 \\
\hline FFSTDNT02HOGJ9 & Glyma13g17420.1/Nod100 & 114 & $2.00 \mathrm{E}-27$ & 1 & 0 & 0 & 0 \\
\hline FGQ137402JLLRK & Glyma14g01160.1 & 144 & $1.00 \mathrm{E}-36$ & 0 & 0 & 1 & 0 \\
\hline contig02608 & Glyma14g23780.1 & 365 & 5.00E-102 & 61 & 54 & 83 & 85 \\
\hline contig08886 & Glyma14g23780.1 & 292 & $8.00 \mathrm{E}-80$ & 69 & 1 & 6 & 0 \\
\hline FF0DN3U02FPA3G & Glyma14g23780.1 & 142 & $5.00 \mathrm{E}-36$ & 0 & 0 & 1 & 0 \\
\hline contig28379 & Glyma14g38170.1 & 380 & $2.00 \mathrm{E}-106$ & 95 & 85 & 73 & 76 \\
\hline contig33554 & Glyma14g38170.1 & 338 & $1.00 \mathrm{E}-93$ & 0 & 63 & 40 & 8 \\
\hline FF0DN3U01BBYR5 & Glyma14g38170.1 & 112 & $5.00 \mathrm{E}-27$ & 0 & 1 & 0 & 0 \\
\hline contig18937 & Glyma15g00620.1 & 113 & 4.00E-26 & 3 & 0 & 0 & 0 \\
\hline contig01826 & Glyma15g35070.1 & 170 & $5.00 \mathrm{E}-43$ & 17 & 10 & 17 & 0 \\
\hline contig05700 & Glyma15g35070.1 & 202 & $2.00 \mathrm{E}-52$ & 49 & 34 & 35 & 10 \\
\hline
\end{tabular}


Table 9 Analysis of tentative nodulation genes from 454 unigenes of common bean (Continued)

\begin{tabular}{|c|c|c|c|c|c|c|c|}
\hline FF0DN3U02GRTQS & Glyma15g35070.1 & 112 & $9.00 \mathrm{E}-27$ & 0 & 1 & 0 & 0 \\
\hline contig04872 & Glyma16g21620.1 & 699 & 0 & 13 & 10 & 26 & 35 \\
\hline contig10706 & Glyma16g21620.1 & 229 & $1.00 \mathrm{E}-60$ & 6 & 1 & 0 & 0 \\
\hline contig28435 & Glyma16g21620.1 & 182 & $2.00 \mathrm{E}-46$ & 8 & 28 & 29 & 1 \\
\hline contig06537 & Glyma17g03340.1 & 144 & $6.00 \mathrm{E}-36$ & 7 & 16 & 14 & 77 \\
\hline contig29092 & Glyma17g03340.1 & 220 & $1.00 \mathrm{E}-58$ & 6 & 11 & 3 & 2 \\
\hline contig01836 & Glyma17g08110.1/Nod55-2 & 94.4 & $1.00 \mathrm{E}-20$ & 2 & 1 & 0 & 18 \\
\hline contig06642 & Glyma17g14220.1 & 397 & $3.00 \mathrm{E}-111$ & 183 & 165 & 374 & 19 \\
\hline contig08079 & Glyma17g14220.1 & 315 & $1.00 \mathrm{E}-86$ & 3 & 2 & 4 & 0 \\
\hline FF0DN3U01DP3JJ & Glyma17g14220.1 & 108 & $1.00 \mathrm{E}-25$ & 0 & 0 & 1 & 0 \\
\hline contig04461 & Glyma17g27490.1 & 415 & $1.00 \mathrm{E}-116$ & 6 & 5 & 19 & 5 \\
\hline contig34068 & Glyma18g02230.1/N70 & 324 & $2.00 E-89$ & 75 & 64 & 19 & 0 \\
\hline contig36321 & Glyma18g02230.1/N70 & 318 & 4.00E-92 & 16 & 9 & 16 & 12 \\
\hline FFSTDNT01DXXI7 & Glyma18g02230.1/N70 & 99 & $7.00 \mathrm{E}-23$ & 1 & 0 & 0 & 0 \\
\hline contig34962 & Glyma18g14750.1 & 197 & $1.00 \mathrm{E}-93$ & 25 & 16 & 55 & 41 \\
\hline contig08052 & Glyma19g45310.1 & 333 & $6.00 \mathrm{E}-92$ & 3 & 1 & 1 & 2 \\
\hline contig12852 & Glyma19g45310.1 & 495 & $1.00 \mathrm{E}-140$ & 9 & 0 & 5 & 1 \\
\hline
\end{tabular}

Amount of ss DNA needed for the bulk run depends on the results of the titration run. In emPCR individual ssDNA fragments were first annealed to an oligonucleotide complementary to 'B' adapter covalently bound to DNA capture beads. An emulsion was then prepared by vigorous shaking which created water-in-oil microreactors, each containing a DNA bead with attached sscDNA fragment and all necessary PCR reagents. This emulsion went through a thermocycling reaction that clonally amplified the attached DNA fragments to generate millions of copies of DNA on each bead. After amplification, the emulsion was broken and the beads were recovered and then washed by filtration.

The biotinylated Adapter A, also added during sscDNA construction, was utilized next to facilitate capture and recovery of all DNA positive beads using a streptavidin-coated magnetic bead. The capture beads without bound DNA did not bind to the streptavidin beads and were washed away. The remaining beads were then subjected to a chemical melt which denatured the bound ds-cDNA and thus separated the amplified capture beads from the magnetic beads. The mixture was magnetized again and the supernatant was recovered. This recovered supernatant contained the collection of ss-cDNA positive beads. A sequencing primer was then annealed to Adapter A and approximately 40,000 and $1,500,000$ beads were loaded into a $1 / 16^{\text {th }}$ region (for titration) and into two half regions (Bulk run) respectively, of a $70 \times 75$ PicoTiterPlate (PTP) which contains approximately 1 million wells with an average diameter of $44 \mu \mathrm{m}$. This was followed by loading of the packing beads and enzyme beads. The PTP was then placed onto the GSFLX Genome Sequencer and bases (TACG) are sequentially flowed (100 cycles) across the plate. Each time a base is incorporated a chemical reaction occurs resulting in the emission of light. As chemilluminescent signal is generated it is captured by the onboard camera and processed in real time by the on-rig computer into digital images, from which DNA sequence and quality scores are generated. The raw sequences are available in SRA at NCBI under the accession number SRA028837.

\section{SSR analysis}

To find SSRs in the data sets, the MISA program (a PERL-program written by Thomas Thiel; http://pgrc. ipk-gatersleben.de/misa) was used. The program can identify not only perfect SSRs but also compound SSRs which are interrupted by a certain number of bases. SSRs were considered to contain motifs which were between two and six nucleotides in size in this study. Dinucleotide, trinucleotide, tetranucleotide, pentanucleotide, and hexanucleotide repeats with minimum lengths of $12 \mathrm{bp}, 15 \mathrm{bp}, 20 \mathrm{bp}, 25 \mathrm{bp}$ and $30 \mathrm{bp}$, respectively, were considered as SSRs, as similarly defined in barley studies [49].

\section{Assembly and annotation of 454-reads}

The adaptor sequences are identified and trim positions are changed in sff files using cross_match http://www. phrap.org, sff tools from Roche https://www.rocheapplied-science.com/index.jsp and in-house Java scripts. Short sequences (less than $25 \mathrm{nt}$ ) were filtered and then sequences are assembled using Newbler software from Roche, using the modified sff files and default parameters. The resulting contigs and singletons that are more than $100 \mathrm{nt}$ were annotated separately using BLAST [50]. The databases used were non-redundant 
protein database and bean ESTs from NCBI http://www. ncbi.nlm.nih.gov, Arabidopsis protein database from TAIR http://www.arabidopsis.org/, Soybean, Medicago and Lotus gene indices from DFCI http://compbio.dfci. harvard.edu/tgi/ and rice protein database from Gramene http://www.gramene.org/. In all cases the E-value cut off was $10^{-5}$. Top1 hits from the BLAST were parsed and used for annotation and further analysis of bean 454- contigs and singletons. The GO annotation was carried out using BLAST results against Arabidopsis protein sequences.

\section{Transcription factor analysis}

We used BLAST results of bean unique sequences against Arabidopsis proteins, to identify bean sequences homologous to Arabidopsis transcription factor genes from PlnTFDB http://plntfdb.bio.uni-potsdam.de/v3.0/ [35].

\section{Validation of expression patterns of selected unigenes}

Total RNA was isolated from leaf, flower, pod and root tissues using TRIzol reagent (Invitrogen, Carlsbad, CA). Total RNA was digested with rDNAse (Ambion Inc, USA) to remove contaminated DNA. RNA concentration was measured by ND-2000 spectrophotometer (NanoDrop products, Wilmington, DE) and $10 \mu \mathrm{g}$ of total RNA was reverse transcribed using ProtoScript ${ }^{\mathbb{R}}$ M-MuLV First Strand cDNA Synthesis Kit (New England BioLabs, Beverley, MA). Removal of genomic DNA in RNA samples was further confirmed by amplifying the genomic DNA, positive cDNA, negative cDNA control with common bean molecular marker SK14 (Figure $6 \mathrm{~A}$ ) and contig 32,565 primers designed to amplify intron flanking region (Figure 6B). The 48 contigs were verified as shown in Figure 4. Randomly chosen contigs listed in Table 4 were selected for expression analysis by quantitative PCR. Concentrations of cDNA from all the tissues were equalized for reverse transcriptase and quantitative PCR experiments. The gene cons 7 was used as an endogenous control $[7,27]$ and leaf tissue was used as a reference sample. Real time PCR analysis was performed in 96 well format (7500 Real-Time system, Applied Biosystems, Foster City, CA) using SYBR dye. Gene expression analysis was carried out by Comparative $2^{-\Delta \Delta C T}$ method [51] where $\Delta \Delta C T=(C T$ of contig CT of cons7) tissue to be observed - (CT of contig.x CT of cons7) leaf tissue.

\section{Acknowledgements}

VK acknowledges funding by NSF grant EPS-0814251. Support for KM was provided by USDA grant 2007-03409 to VK. Support for ZL was provided by USDA grant 2008-02675 to VK. The authors also acknowledge the assistance of Mollee Crampton and Meredith Biedrzycki in editing of the manuscript.

\section{Author details}

'College of Agriculture \& Related Sciences, Delaware State University, Dover, DE 19901, USA. ${ }^{2}$ Department of Plant \& Soil Sciences and Delaware Biotechnology Institute, University of Delaware, Newark, DE 19711, USA. ${ }^{3}$ W. M. Keck Center for Comparative and Functional Genomics, University of Illinois, Urbana-Champaign, IL 61801, USA. ${ }^{4}$ Center for Integrated Biological and Environmental Research, Delaware State University, Dover, DE 19901, USA.

\section{Authors' contributions}

VK conceived and designed the research, and contributed to coordination of the analysis and experimental validation, and to the writing of the manuscript. ZL helped with experimental verification, analysis of sequence data, and contributed to writing of the manuscript. BM helped with conceiving and analysis of the research, and editing of the manuscript. JT conducted the bioinformatics analysis and contributed to the writing of the methods for 454 sequencing and the manuscript. KM helped with experimental verification and contributed to the writing of the manuscript. All authors read and approved the final manuscript.

Received: 22 June 2011 Accepted: 11 October 2011

Published: 11 October 2011

\section{References}

1. McConnell M, Mamidi S, Lee R, Chikara S, Rossi M, Papa R, McClean P: Syntenic relationships among legumes revealed using a gene-based genetic linkage map of common bean (Phaseolus vulgaris L.). Theor Appl Genet 2010, 121:1103-1116.

2. Lavin M, Herendeen PS, Wojjciechowski MF: Evolutionary rate analysis of leguminosae implicates a rapid diversification of lineages during the tertiary. Syst Biol 2005, 54:575-594.

3. Schlueter JA, Dixon P, Granger C, Grant D, Clark L, Doyle JJ, Shoemaker RC: Mining the EST databases to determine evolutionary events in the legumes and grasses. Genome 2004, 47:868-876.

4. Galeano CH, Fernandez AC, Gomez M, Blair MW: Single strand conformation polymorphism based SNP and Indel markers for genetic mapping and synteny analysis of common bean (Phaseolus vulgaris L.). BMC Genomics 2009, 10:629.

5. Arumuganthan K, Earle E: Nuclear DNA content of some important plant species. Plant Mol Biol Rep 1991, 9:208-218.

6. Bennett MD, Leitch IJ: Nuclear DNA amounts in angiosperms. Annals of Botany 1995, 76:113-116.

7. Thibivilliers S, Joshi T, Campbell KB, Scheffler B, Xu D, Coopers B, Nguyen HT, Stacey G: Generation of Phaseolus vulgaris ESTs and investigation of their regulation upon Uromyces appendiculatus infection. BMC Plant Biol 2009, 9:46.

8. McClean PE, Cannon S, Gepts P, Hudson M, Jackson S, Rokhsar D, Schmutz J, Vance C: Towards a whole genome sequence of common bean (Phaseolus vulgaris): Background, Approaches, Applications.[http:// www.csrees.usda.gov/business/reporting/stakeholder/pdfs/ pl_common_bean.pdf], Executive Summary.

9. Ramirez M, Graham MA, Blanco-Lopez L, Silvente S, Medrao-soto A, Blair MW, Hernandez G, Vance CP, Lara M: Sequencing and analysis of common bean ESTs. Building a foundation for functional genomics. Plant Physiology 2005, 137:1211-1227.

10. Melotto M, Monteiro-Vitorello CB, Bruschi AG, Camargo LE: Comparative bioinformatic analysis of genes expressed in common bean (Phaseolus vulgaris L.) seedlings. Genome 2005, 48:562-570.

11. Tian J, Venkatachalam P, Liao H, Yan X, Raghothama K: Molecular cloning and characterization of phosphorous starvation responsive genes in common bean (Phaseolus vulgaris L.). Planta 2007, 227:151-165.

12. Sanger F, Nicklen S, Coulson AR: DNA sequencing with chain-terminating inhibitors. Proc Natl Acad Sci USA 1977, 74:5463-5467.

13. Mardis ER: The impact of next-generation sequencing technology on genetics. Trends in Genetics 2008, 24:133-141.

14. Vera J, Wheat C, Fescemyer H, Frilander M, Crawford D, Hanski I, Marden J: Rapid transcriptome characterization for a nonmodel organism using 454 pyrosequencing. Mol Ecol 2008, 17:1636-1647.

15. Margulies M, Egholm M, Altman WE, Attya S, Bader JS, Bemben LA, Berka J, Braverman MS, Chen YJ, Chen Z, Dewell SB, Du L, Fierro JM, Gomes XVs, Goodwin BC, He W, Helgesen S, Ho CH, Irzyk GP, Jando SC, Alenquer MLI, 
Jarvie TP, Jirage KB, Kim JB, Knight JK, Lanza JR, Leamon JH, Lefkowitz SM, Lei M, Li J, Lohman KL, Lu H, Makhijani VB, McDade KE, McKenna MP, Myers EW, Nickerson E, Nobile JR, Plant R, Puc BP, Ronan MT, Roth GT, Sarkis GJ, Simons JF, Simpson JW, Srinivasan M, Tartaro KR, Tomasz A, Vogt KA, Volkmer GA, Wang SH, Wang Y, Weiner MP, Yu P, Begley RF, Rothberg JM: Genome sequencing in microfabricated high-density picolitre reactors. Nature 2005, 4437:376-80.

16. Macas J, Neumann P, Navratilova A: Repetitive DNA in the pea (Pisum sativum L.) genome: comprehensive characterization using 454 sequencing and comparison to soybean and Medicago truncatula. BMC Genomics 2007, 8:427.

17. Cheung F, Haas B, Goldberg S, May G, Xiao Y, Town C: Sequencing Medicago truncatula expressed sequenced tags using 454 Life Science technology. BMC Genomics 2006, 7:272-282.

18. Emrich SJ, Barbazuk WB, Li L, Schnable PS: Gene discovery and annotation using LCM-454 transcriptome sequencing. Genome Res 2007, 17:69-73.

19. Vega-Arreguin J, Ibarra-Laclette E, Jimenez-Moraila B, Martinez O, VielleCalzada J, Herrera-Estrella L, Herrera-Estrella A: Deep sampling of the Palomero maize transcriptome by a high throughput strategy of pyrosequencing. BMC Genomics 2009, 10:299.

20. Weber AP, Weber KL, Carr K, Wilkerson C, Ohlrogge JB: Sampling the Arabidopsis transcriptome with massively parallel pyrosequencing. Plant Physiol 2007, 144:32-42

21. Velasco R, Zharkikh A, Troggio M, Cartwright DA, Cestaro A, Pruss D, Pindo M, Fitzgerald LM, Vezzulli S, Reid J, Malacarne G, lliev D, Coppola G, Wardell B, Micheletti D, Macalma T, Facci M, Mitchell JT, Perazzolli M, Eldredge G, Gatto P, Oyzerski R, Moretto M, Gutin N, Stefanini M, Chen Y, Segala C, Davenport C, Demattte L, Mraz A, Battilana J, Stormo K, Costa F, Tao Q, Si-Ammour A, Harkins T, Lackey A, Perbost C, Taillon B, Stella A, Solovyev V, Fawcett JA, Sterck L, Vandepoele K, Grando SM, Toppo S, Moser C, Lanchbury J, Bogden R, Skolnick M, Sgaramella V, Bhatnagar SK, Fontana P, Gutin A, Van de Peer Y, Salamini F, Viola R: A high quality draft consensus sequence of the genome of a heterozygous grapevine variety. PLOS ONE 2007, 2:e1326.

22. McClean PE, Mamidi S, McConnell M, Chikara S, Lee R: Synteny mapping between common bean and soybean reveals extensive blocks of shared loci. BMC Genomics 2010, 11:184.

23. WebReference 1: Sierra a new pinto bean for Michigan. Michigan State University;[http://web2.msue.msu.edu/Bulletins/Bulletin/PDF/Historical/ finished_pubs/e2494/e2494-1994.pdf].

24. Varshney R, Close T, Singh N, Hoisington D, Cook D: Orphan legume crops enter the genomics era! Curr Opin Plant Biol 2009, 12:202-210.

25. Schlueter JA, Goicoechea JL, Collura K, Gill N, Lin JY, Yu Y, Kudrna D, Zuccolo A, Vallejos CE, Munoz-Torres M, Blair MW, Tohme J, Tomkins J, McClean P, Wing RA, Jackson SA: BAC-end sequence analysis and a draft physical map of the common bean (Phaseolus vulgaris L.) genome. Trop Plant Biol 2008, 1:40-48.

26. Wong $\mathrm{H}$, Zhang $X Q$, Wang $H X, N g$ TB: A mitogenic defensin from white cloud beans (Phaseolus vulgaris). Peptides 2006, 27:2075-2081.

27. Libault M, Thibivilliers S, Bilgin DD, Radwan O, Benitez M, Clough SJ, Stacey G: Identification of four soybean reference genes for gene expression normalization. The Plant Genome 2008, 1:44-54

28. Kantety RV, La Rota M, Matthews DE, Sorrells ME: Data mining for simple sequence repeats in expressed sequence tags from barley, maize, rice, sorghum and wheat. Plant Mol Biol 2002, 48:501-510.

29. Gao L, Tang J, Li H, Jia J: Analysis of microsatellites in major crops assessed by computational and experimental approaches. Mol Breeding 2003, 12:245-261.

30. Blair MW, Torres MM, Giraldo MC, Pedraza F: Development and diversity of Andean-derived, gene-based microsatellites for common bean (Phaseolus vulgaris L.). BMC Plant Biol 2009, 9:100.

31. Blair MW, Hurtado N, Chavarro CM, Munoz-Torres MC, Giraldo MC, Pedraza F, Tomkins J, Wing R: Gene-based SSR markers for common bean (Phaseolus vulgaris L.) derived from root and leaf tissue ESTs: an integration of the BMC series. BMC Plant Biol 2011, 11:50.

32. Cordoba JM, Chavarro C, Schlueter JA, Jackson SA, Blair MW: Integration of physical and genetic maps of common bean through BAC-derived microsatellite markers. BMC Genomics 2010, 11:436.

33. Gupta PK, Rustgi S, Sharma S, Singh R, Kumar N, Balyan HS: Transferable EST-SSR markers for the study of polymorphism and genetic diversity in bread wheat. Mol Genet Genomics 2003, 270:315-323.
34. Mukhtar MS, Deslandes L, Auriac MC, Marco Y, Somssich IE: The Arabidopsis transcription factor WRKY27 influences wilt disease symptom development caused by Ralstonia solanacearum. Plant J 2008, 56:935-947.

35. Perez-Rodriguez P, Riano-Pachon DM, Correa LGG, Rensing SA, Kersten B, Mueller-Roeber B: PInTFDB: updated content and new features of the plant transcription factor database. Nucleic Acids Res 2009, 38:D822-D827.

36. Mochida K, Yoshida T, Sakurai T, Yamaguchi-Shinozaki K, Shinozaki K, Tran LS: LegumeTFDB: an integrative database of Glycine max, Lotus japonicus and Medicago truncatula transcription factors. Bioinformatics 2010, 26:290-291.

37. Borevitz JO, Xia Y, Blount J, Dixon RA, Lamb C: Activation tagging identifies a conserved MYB regulator of phenylpropanoid biosynthesis. Plant Cell 2000, 12:2383-2394.

38. Oppenheimer D, Herman PL, Sivakumaran S, Esch J, Marks MD: A myb gene required for leaf trichome differentiation in Arabidopsis is expressed in stipules. Cell 1991, 67:483-493.

39. Olsen AN, Ernst HA, Leggio LL, Skriver K: NAC transcription factors: structurally distinct, functionally diverse. Trends in Plant Sci 2005, 10:79-87.

40. Hegedus D, Yu M, Baldwin D, Gruber M, Sharpe A, Parkin I, Whitwill S, Lydiate D: Molecular characterization of Brassica napus NAC domain transcriptional activators induced in response to biotic and abiotic stress. Plant Mol Biol 2003, 53:383-397.

41. Ohnishi T, Sugahara S, Yamada T, Kikuchi K, Yoshiba Y, Hirano HY, Tsutsumi N: OsNAC6, a member of the NAC gene family, is induced by various stresses in rice. Genes Genet Syst 2005, 80:135-139.

42. Peng $H$, Cheng HY, Yu XW, Shi QH, Zhang H, Li JG, Ma H: Characterization of a chickpea (Cicer arietinum L.) NAC family gene, CarNAC5, which is both developmentally-and stress-regulated. Plant Physiol Biochem 2009, 47:1037-1045.

43. Pinheiro GL, Marques CS, Costa MD, Reis PA, Alves MS, Carvalho CM, Fietto LG, Fontes EP: Complete inventory of soybean NAC transcription factors: sequence conservation and expression analysis uncover their distinct roles in stress response. Gene 2009, 444:10-23.

44. Xia N, Zhang G, Liu XY, Deng L, Cai GL, Zhang Y, Wang XJ, Zhao J, Huang LL, Kang ZS: Characterization of a novel wheat NAC transcription factor gene involved in defense response against stripe rust pathogen infection and abiotic stresses. Mol Biol Rep 2010, 37(8):3703-12.

45. Marmorstein R: Transcription initiation at its most basic level. Cell 2003, 115:370-372.

46. Roberti M, Polosa PL, Bruni F, Manzari C, Deceglie S, Gadaleta MN, Cantatore $P$ : The MTERF family proteins: mitochondrial transcription regulators and beyond. Biochim Biophys Acta 2009, 1787:303-311.

47. Lin R, Ding L, Casola C, Ripoll DR, Feschotte C, Wang H: Transposasederived transcription factors regulate light signaling in Arabidopsis. Science 2007, 318:1302-1305.

48. Schmutz J, Cannon SB, Schlueter J, Ma J, Mitros T, Nelson W, Hyten DL, Song Q, Thelen JJ, Cheng J, Xu D, Hellsten U, May GD, Yu Y, Sakurai T, Umezawa T, Bhattacharyya MK, Sandhu D, Valliyodan B, Lindquist E, Peto M, Grant D, Shu S, Goodstein D, Barry K, Futrell-Griggs M, Abernathy B, Du J, Tian Z, Zhu L, Gill N, Joshi T, Libault M, Sethuraman A, Zhang XC, Shinozaki K, Nguyen HT, Wing RA, Cregan P, Specht J, Grimwood J, Rokhsar D, Stacey G, Shoemaker RC, Jackson SA: Genome sequence of the palaeopolyploid soybean. Nature 2010, 463:178-183.

49. Thiel T, Michalek W, Varshney RK, Graner A: Exploiting EST databases for the development and characterization of gene-derived SSR-markers in barley (Hordeum vulgare L.). Theor Appl Genet 2003, 106:411-422.

50. Altschul SF, Gish W, Miller W, Myers EW, Lipman DJ: Basic local alignment search tool. J Mol Biol 1990, 215:403-410.

51. Livak KJ, Schmittgen TD: Analysis of relative gene expression data using real-time quantitative PCR and the $2(-\Delta \Delta C(T))$ Method. Methods 2001, 25:402-408.

\section{doi:10.1186/1471-2229-11-135}

Cite this article as: Kalavacharla et al:: Identification and analysis of common bean (Phaseolus vulgaris L.) transcriptomes by massively parallel pyrosequencing. BMC Plant Biology 2011 11:135. 